\title{
TempestExtremes v2.1: a community framework for feature detection, tracking, and analysis in large datasets
}

\author{
Paul A. Ullrich ${ }^{1}$, Colin M. Zarzycki ${ }^{2}$, Elizabeth E. McClenny ${ }^{1}$, Marielle C. Pinheiro ${ }^{1}$, Alyssa M. Stansfield ${ }^{3}$, and \\ Kevin A. Reed ${ }^{3}$ \\ ${ }^{1}$ Department of Land, Air and Water Resources, University of California, Davis, CA, USA \\ ${ }^{2}$ Department of Meteorology and Atmospheric Science, Pennsylvania State University, University Park, PA, USA \\ ${ }^{3}$ School of Marine and Atmospheric Sciences, State University of New York at Stony Brook, Stony Brook, NY, USA
}

Correspondence: Paul A. Ullrich (paullrich@ucdavis.edu)

Received: 8 September 2020 - Discussion started: 20 January 2021

Revised: 22 June 2021 - Accepted: 11 July 2021 - Published: 13 August 2021

\begin{abstract}
TempestExtremes (TE) is a multifaceted framework for feature detection, tracking, and scientific analysis of regional or global Earth system datasets on either rectilinear or unstructured/native grids. Version 2.1 of the TE framework now provides extensive support for examining both nodal (i.e., pointwise) and areal features, including tropical and extratropical cyclones, monsoonal lows and depressions, atmospheric rivers, atmospheric blocking, precipitation clusters, and heat waves. Available operations include nodal and areal thresholding, calculations of quantities related to nodal features such as accumulated cyclone energy and azimuthal wind profiles, filtering data based on the characteristics of nodal features, and stereographic compositing. This paper describes the core algorithms (kernels) that have been added to the TE framework since version 1.0, including algorithms for editing pointwise trajectory files, composition of fields around nodal features, generation of areal masks via thresholding and nodal features, and tracking of areal features in time. Several examples are provided of how these kernels can be combined to produce composite algorithms for evaluating and understanding common atmospheric features and their underlying processes. These examples include analyzing the fraction of precipitation from tropical cyclones, compositing meteorological fields around extratropical cyclones, calculating fractional contribution to poleward vapor transport from atmospheric rivers, and building a climatology of atmospheric blocks.
\end{abstract}

\section{Introduction}

For many atmospheric and oceanic features, automated object identification and tracking in large datasets has enabled the targeted scientific exploration of feature-specific processes. Software tools for feature tracking, colloquially referred to as "trackers", are valuable for evaluating model performance (Davini and D'Andrea, 2016; Stansfield et al., 2020), understanding upstream process drivers, such as large-scale meteorological patterns (e.g., Grotjahn et al., 2016), and projecting future changes in feature characteristics and climatology (Roberts et al., 2020a). When wellengineered, these automated tools provide a means for analyzing the multiple petabytes of climate data now available and anticipated in the next decade (Schnase et al., 2016; Hassani et al., 2019). Since its introduction, TempestExtremes (TE; Ullrich and Zarzycki, 2017) has been continuously augmented with new kernels - that is, basic data operators that can act as building-blocks for more complicated tracking algorithms - designed to streamline data analysis and generalize capabilities present in other trackers. These kernels thus provide more options and flexibility in exploring the space of trackers for each feature and enable a deeper understanding of how robust a given scientific conclusion is with respect to the choice of tracker. We describe the most significant of these updates and provide a number of use cases to demonstrate TE's functionality for real scientifically driven case studies.

Numerous publications over the past several decades have presented automated algorithms for the identification of both 
nodal (i.e., pointwise) and areal atmospheric features. Appendices A-C of Ullrich and Zarzycki (2017) summarized dozens of such automated algorithms for extratropical cyclones, tropical cyclones, and tropical easterly waves. Even so, work to identify optimal tracking criteria continues $(\mathrm{Mu}-$ rata et al., 2019). Beyond these traditionally tracked features, many recent papers have focused on defining regionally relevant features such as monsoonal lows and depressions associated with heavy precipitation in monsoonal regions (Hurley and Boos, 2015; Vishnu et al., 2020). Areal feature tracking algorithms have also been developed for clouds (Heikenfeld et al., 2019), atmospheric rivers (Shields et al., 2018; Rutz et al., 2019), atmospheric blocking (Scherrer et al., 2006), mesoscale convective systems (Prein et al., 2017; Feng et al., 2018), precipitation clusters (Clark et al., 2014; Pendergrass et al., 2016), convectively generated outflow boundaries (Chipilski et al., 2018), gust fronts (Delanoy and Troxel, 1993), and frontal systems (Hope et al., 2014; Schemm et al., 2015; Parfitt et al., 2017). Both nodal and areal algorithms generally feature a similar set of kernels, motivating the development of a single package encompassing relevant capabilities. For example, the majority of detection algorithms are built upon an algorithmic paradigm known as MapReduce (Dean and Ghemawat, 2008), in which individual time slices are independently assessed (an embarrassingly parallel "map" operation) then combined via a serial "reduce" operation. By building a single framework for distributing time slices to different feature identification algorithms, then combining multiple features into a single dataset, we can avoid duplication of this infrastructure across multiple trackers. Leveraging commonalities such as these enables improvements in algorithmic efficiency to be simultaneously administered to multiple trackers and reduces redundancies from algorithmic validation and testing.

TE has been engineered with the goal of providing a comprehensive and user-friendly toolbox for feature tracking in model, reanalysis, or observational data products. It features a set of core design principles to enable its easy application in scientific analyses:

- Kernels are encapsulated in a variety of executables that are fully configurable from the command line (i.e., containing no hard-coded thresholds). Thus the processing operations performed by TE can be easily conveyed simply by communicating the relevant command(s).

- Many of the finer details about the structure of climate datasets are abstracted through the use of physically motivated kernels (such as the closed contour operator), physically based units, and internal indexing with climate and forecast $(\mathrm{CF})$ compliant time variables.

- The data analysis capabilities are designed to be highthroughput, readily usable, and standardized. All TE functionality is implemented in optimized and (where appropriate) parallelized $\mathrm{C}++$.
- It is designed to work with "big data", enabling significant data volume reduction by isolating characteristics of individual features rather than full fields.

- Kernels are designed for arbitrarily grids, recognizing that climate models have largely moved away from latitude-longitude grids and towards quasi-uniform grids (Ullrich et al., 2017).

- All TE code is open-source, publicly developed, and distributed via GitHub with permissive open-source licensing.

These principles complement the underlying foci motivating TE's development: robustness, usability, maintainability, and extensibility. To the best of the authors' knowledge, no other comprehensive toolkit exists for general nodal and areal feature tracking in Earth system datasets.

The remainder of this paper follows an analogous structure to Ullrich and Zarzycki (2017). Section 2 describes the core algorithms and kernels now available in TE v2.1. Section 3 presents several examples of how these kernels can be combined to form recipes for tracking tropical cyclones (TCs), for calculating fractional contribution of precipitation from TCs, for tracking and compositing extratropical cyclone fields, for tracking atmospheric rivers, and for tracking atmospheric blocks. A summary of results and future work is given in Sect. 4.

\section{TempestExtremes algorithms and kernels}

In this section we describe the kernels available in the TE software package, organized by executable, with an emphasis on additions since TE v1.0. Technical details on the operation of TempestExtremes can be found in the user guide (Ullrich, 2020).

\subsection{DetectNodes and StitchNodes}

DetectNodes (formerly DetectCyclonesUnstructured) is used for the detection of nodal feature candidates and corresponds to the parallel "map" step in the "MapReduce" framework - that is, candidate points are selected based on information at a single time slice. DetectNodes is typically followed by StitchNodes, which represents the serial "reduce" operation in the processing chain. StitchNodes connects nodal features in time and produces paths associated with singular features. Both of these executables and their algorithmic kernels are described in Ullrich and Zarzycki (2017), although version 2.1 now supports the use of physical time units for thresholds and time subsetting. For example, mint ime may be specified as a minimum number of time slices (e.g., "5") or as the minimum number of hours between the first and last candidate in a path (e.g., "2 $4 \mathrm{~h}$ ").

DetectNodes and StitchNodes output trajectories in a format originally defined by the Geophysical Fluid Dynamics 
Table 1. Functions implemented in NodeFileEditor as of TempestExtremes v2.1.

\begin{tabular}{|c|c|}
\hline Operator & Description \\
\hline eval_ace & $\begin{array}{l}\text { Calculate the instantaneous accumulated cyclone energy (ACE; Bell et al., 2000), equal to } 10^{-4} u_{\mathrm{kt}, \mathrm{max}}^{2} \text {, where } \\
u_{\mathrm{kt}, \mathrm{max}} \text { is the maximum wind speed within a prescribed radius of the nodal feature in knots. We use a value of } \\
1.94384 \mathrm{kn}\left(\mathrm{m} \mathrm{s}^{-1}\right)^{-1} \text { to convert meters per second }\left(\mathrm{m} \mathrm{s}^{-1}\right) \text { to knots }(\mathrm{kn}) \text {. }\end{array}$ \\
\hline eval_acepsl & $\begin{array}{l}\text { Approximate ACE using sea level pressure (SLP) to predict surface wind speed (ACEPSL). Currently, ACEPSL } \\
\text { is calculated as ACE but using } u_{\mathrm{kt}, \max }=1.94384 \mathrm{kn}\left(\mathrm{m} \mathrm{s}^{-1}\right)^{-1} \times 3.92 \times\left(1016.0 \mathrm{hPa}-\mathrm{slp}_{\min }\right)^{0.644} \text { (Holland, } \\
\text { 2008), where slpmin is the minimum SLP within a prescribed radius. }\end{array}$ \\
\hline eval_ike & $\begin{array}{l}\text { Calculate the instantaneous integrated kinetic energy (Powell and Reinhold, 2007), defined as } \sum_{i} \frac{1}{2} u_{i}^{2} A_{i} \text {, where } \\
u_{i} \text { is the magnitude of the wind speed at that grid cell (in } \mathrm{m} \mathrm{s}^{-1} \text { ), } A_{i} \text { is the area of that grid cell (in } \mathrm{m}^{2} \text { ), and } \\
\text { the sum is taken over all grid cells within a prescribed radius. }\end{array}$ \\
\hline eval_pdi & $\begin{array}{l}\text { Calculate the power dissipation index (Emanuel, 2005), defined as } u_{\max }^{3} \text {, where } u_{\max } \text { is the maximum wind } \\
\text { speed within a prescribed radius (in } \mathrm{m} \mathrm{s}^{-1} \text { ). }\end{array}$ \\
\hline radial_profile & $\begin{array}{l}\text { Develop a radial profile of the specified variable at each time slice around the nodal feature point by binning by } \\
\text { radial distance and averaging grid point values. The output is expressed using Python array syntax. }\end{array}$ \\
\hline radial_wind_profile & $\begin{array}{l}\text { This is like radial_profile but for the radial and azimuthal wind speed. The radial and azimuthal components are } \\
\text { computed by projecting the } 2 \mathrm{D} \text { velocity at each grid point onto the radial and azimuthal vector fields around } \\
\text { each nodal feature prior to binning. }\end{array}$ \\
\hline last where & $\begin{array}{l}\text { Given an array as input, such as the output of radial_profile, identify the distance or index of the array that } \\
\text { satisfies a given threshold. For example, this operator is used for determining the radius at which azimuthal } \\
\text { wind speed is greater than } 8 \mathrm{~m} \mathrm{~s}^{-1} \text {. }\end{array}$ \\
\hline value & Given an array, extract the value at the specified index using linear interpolation where needed. \\
\hline max_closed_contour & $\begin{array}{l}\text { For a given field, determine the largest value that satisfies the closed contour criteria (see Ullrich and Zarzycki, } \\
2017 \text {, Sect. 2.6) around each nodal feature (see Algorithm 1). }\end{array}$ \\
\hline region_name & $\begin{array}{l}\text { Given the names and coordinates of polygons in longitude-latitude space, identify the name of the region for a } \\
\text { given pointwise feature. Each point is identified as being in a given region using a straight-line test along lines } \\
\text { of constant latitude. If the number of intersections with edges of the polygon is odd (even), then the point is } \\
\text { inside (outside). }\end{array}$ \\
\hline
\end{tabular}

Laboratory (GFDL) tropical cyclone tracker (TSTORMS; Vitart et al., 1997; Zhao et al., 2009). These files are generally referred to as nodefiles.

\subsection{NodeFileEditor}

NodeFileEditor is a new addition to TE for editing nodefiles. It includes options for (1) appending new details to trajectories, such as radial wind profiles or accumulated cyclone energy, (2) removing certain columns from nodefiles, or (3) filtering trajectories or points along a trajectory, e.g., when outside of a specific time interval. A list of functions currently available in NodeFileEditor is given in Table 1. These functions may be chained to perform multiple related operations, such as computing a radial wind profile of a tropical cyclone and then extracting the radius where a particular wind threshold is exceeded. An example of such chaining of commands is given in Sect. 3.3.

Most of the implemented algorithms are straightforward, except formax_closed_contour, whose pseudo-code is provided in Algorithm 1. Intuitively, this algorithm can be thought of as filling up a 3D extruded surface representative of the contours of the field until fluid spills farther out than the prescribed maximum distance. The last height difference is then recorded as the maximum delta for the closed contour.

\subsection{NodeFileFilter}

NodeFileFilter encapsulates algorithms for masking spatial data using nodefile information, i.e., effectively converting nodefiles into binary raster masks at each time slice and (optionally) applying them to available data. Filtering can be performed using the distance from each feature, based on the closed contour of each feature (as described by Algorithm 2), or by thresholding of areal regions that are within a given distance of each nodal feature (as described by Algorithm 3). The latter is useful for identifying, for instance, precipitation clusters associated with tropical cyclones. 


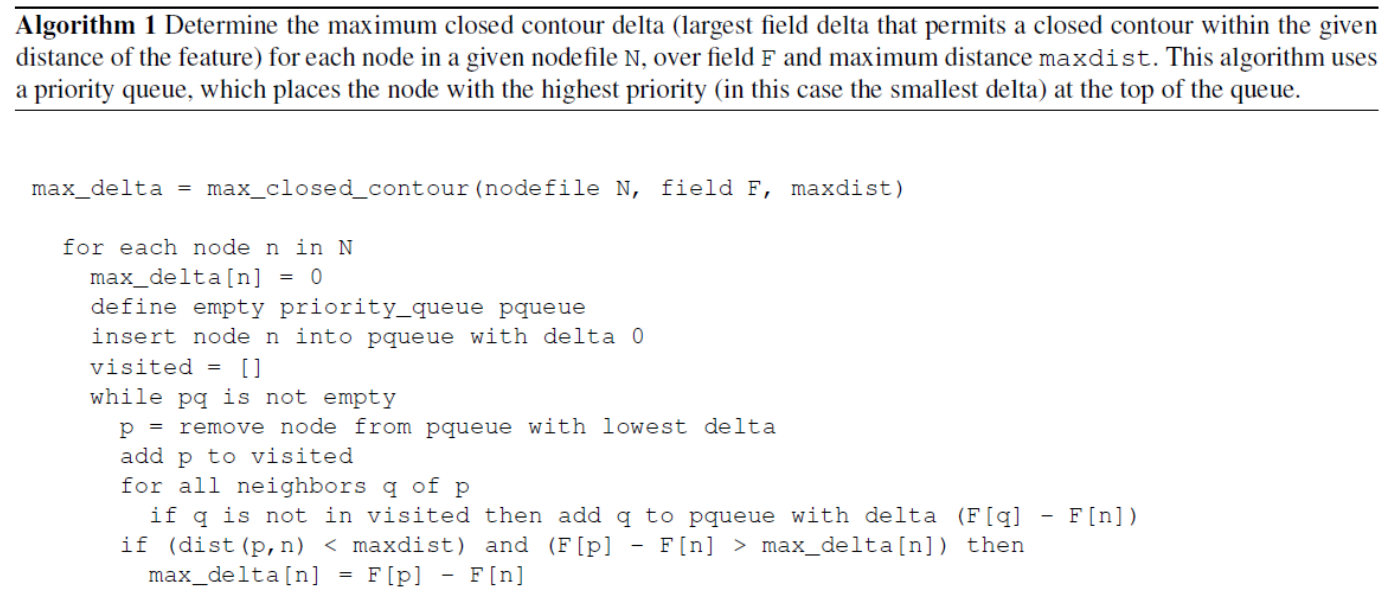

Algorithm 2 Generate a binary mask using a closed contour criterion, given nodefile $\mathrm{N}$, field $\mathrm{F}$, closed contour magnitude
delta, maximum mask distance dist, and maximum distance for minima/maxima search minmaxdist. The functions find_min_near and find_max_near are given by Algorithm 4 in Ullrich and Zarzycki (2017).

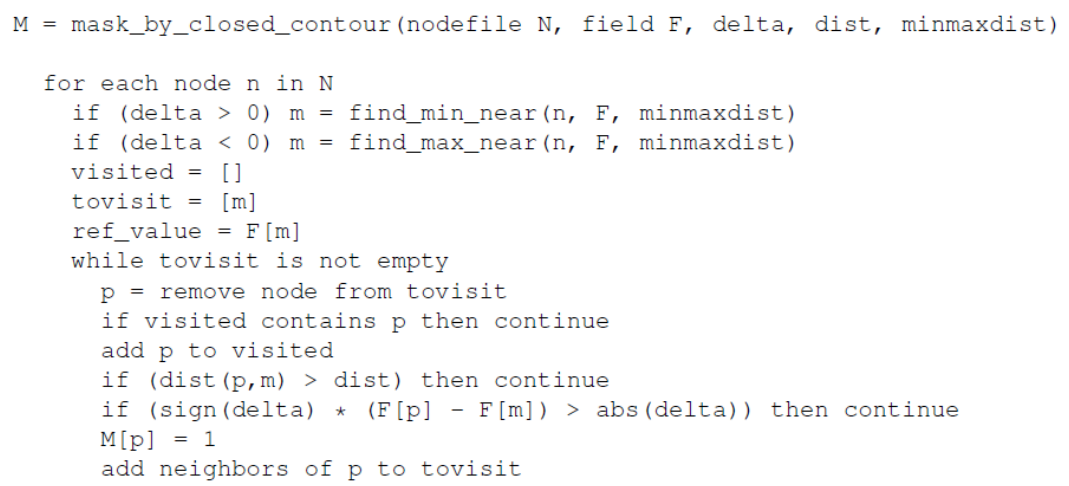

\subsection{NodeFileCompose}

NodeFileCompose includes functionality for snapshotting fields around nodal features (i.e., at each time slice projecting fields onto the stereographic plane centered on a nodal feature) or compositing fields (i.e., averaging snapshots). In the same vein, it also includes functionality for snapshotting or compositing a particular geographic region when a feature is present. Stereographic composites are computed using Algorithm 4. The mathematical operators used for the local stereographic projection are given in Appendix A.

\subsection{DetectBlobs}

DetectBlobs is used for identifying areal features (blobs), such as atmospheric blocks, atmospheric rivers, or precipitation clusters. As with DetectNodes, this executable represents the parallel "map" step in the "MapReduce" framework. Candidate regions are selected based on information at a single time slice, typically simple thresholds such as "all points where precipitation is greater than $1 \mathrm{~mm} \mathrm{~d}^{-1}$ ". Features are marked using a binary mask and output stored in NetCDF format. Contiguous regions may then be excluded based on either geometric thresholds or criteria derived from other variables. DetectBlobs supports MPI-based (message passing interface) parallelism over input files.

\subsection{StitchBlobs}

StitchBlobs is used for tracking areal features (blobs) in time, assigning connected features a unique global ID and/or applying time-dependent criteria to each contiguous region. Given input as a time-dependent binary mask variable, blobs that overlap at sequential time steps will be assigned the same global identifier. The algorithm implemented in TE for connecting blobs in time uses a forward-backward search that can treat the "2D space $+1 \mathrm{D}$ time" object as a single 3D ob- 
Algorithm 3 Generate a binary mask by picking out blobs satisfying a threshold within a given radius of each node. The inputs include the nodefile $\mathrm{N}$, field $\mathrm{F}$, the search distance searchdist, threshold operation threshold, and maximum mask distance maxdist.

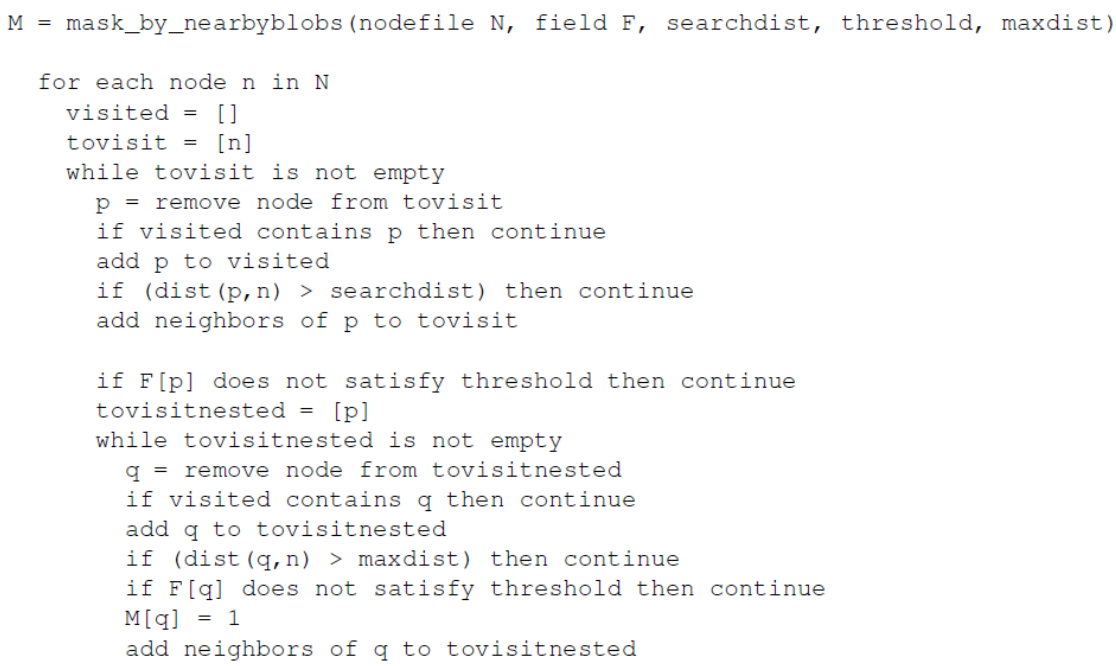

Algorithm 4 Generate a stereographic composite of field $\mathrm{F}$ over the given set of nodes N, generated by DetectNodes. The stereographic grid has resolution res and grid spacing dist, given as the great circle distance along coordinate lines passing through the origin.

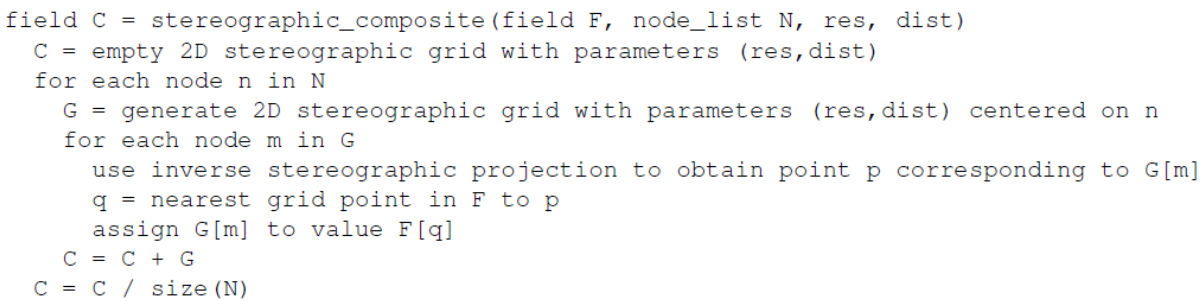

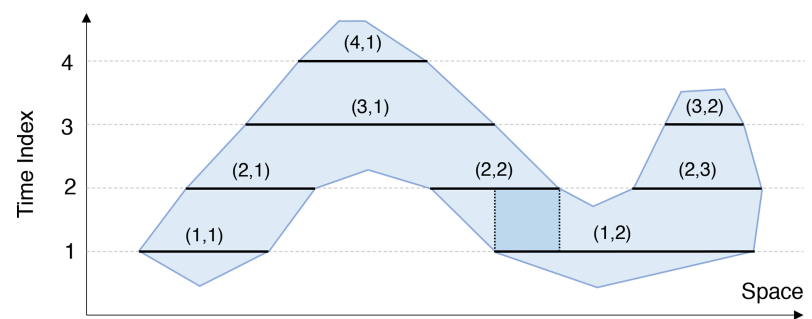

Figure 1. A depiction of algorithms 5 and 6 for forward-backward areal feature search used by StitchBlobs, simplified to show one space dimension (e.g., longitude) and the time dimension.

ject, allowing for both splitting and merging of features in time.
The pseudo-code for this search protocol is provided in algorithms 5 and 6, and its operation is illustrated in Fig. 1. Put briefly, contiguous regions at each time slice are identified using a flood fill algorithm and assigned a unique tag of the form (time ID, blob ID). An additional "merge distance" argument can be specified that merges nearby blobs at each time slice if their perimeters are within this specified distance. A graph is then constructed with each of these tags corresponding to the nodes of the graph. Edges are then added to the graph where a pair of areal features are deemed to be connected in time. Since multiple edges could be generated to or from a feature on a given time slice, multiple mergers or splits may occur simultaneously. Finally, the components of the graph are each assigned a unique global ID, with lower global IDs corresponding to blobs that first appear at earlier times. In Fig. 1, features at time index 1, denoted $(1,1)$ 
and $(1,2)$, will both be assigned the same global ID since they are connected at a later time. Similarly, features at time index 3 , denoted $(3,1)$ and $(3,2)$, are assigned the same global ID since they were connected at an earlier time. Note that global IDs start at 1 and are consecutive thereafter; they are assigned only after connected components of the graph are identified and as such are unrelated to the blob ID on each time slice.

By default, areal features are deemed to be connected in time if they share at least one grid point at subsequent time steps (regardless of the area of that grid point). For example, in Fig. 1, areal regions $(1,1)$ and $(2,1)$ overlap in space and so are deemed to be connected. If a stricter threshold on the overlap area is needed for blobs at sequential time slices to be deemed part of the same cluster, StitchBlobs provides arguments for minimum overlap between the current blob and blobs at the previous and/or next time step. In this example, blob tag $(2,2)$ overlaps only $25 \%$ of the area of blob tag $(1,2)$, meaning that $(2,2)$ and $(1,2)$ are deemed unconnected if the "minimum previous overlap" is greater than $25 \%$. On the other hand blob tag $(1,2)$ covers $50 \%$ of the area of blob tag $(2,2)$, so these two would be deemed unconnected if the "minimum next overlap" is greater than $50 \%$.

\subsection{Other utilities}

In addition to the core functionality described in previous sections, TE also provides a number of other utilities to manage nodefiles, binary masks, and other climatological data relevant to feature tracking. These are briefly mentioned here as this functionality is employed in the composite tracking algorithms and analysis of Sect. 3.

- Climatology is used for constructing climatological time series, including long-term daily, monthly, seasonal, and annual means. It supports parallel execution over files via MPI, as well as arguments that can be used to limit the amount of memory used by each thread.

- FourierFilter is used for Fourier filtering/smoothing of input data series. Although it provides a general implementation that could be used for any dataset, it has primarily been used for smoothing long-term daily means produced from Climatology.

- VariableProcessor provides direct access to TE's internal variable processing capability, allowing arithmetic and grid-based operations to be applied to gridded data files. The operation of this utility is roughly analogous to that of the NetCDF Operator ncap2 (NCO; Zender, 2008).

\section{Selected examples}

In this section we present several examples of tracking and analysis of different features; that is, different recipes for combining the algorithmic kernels described in Sect. 2 to produce composite tracking and analysis algorithms. In all examples, the corresponding TE commands are provided to both demonstrate that they are effective at conveying the operation in a human-readable manner and to enable reproducibility of our results. Past examples from the literature using TE are provided in Sect. 3.1. This is then followed by several examples from TE of feature-based tracking and subsequent analysis. These examples include TC tracking in ERA5, fractional contribution of precipitation from TCs in ERA5 and Tropical Rainfall Measuring Mission (TRMM), atmospheric river tracking in ERA5, extratropical cyclone tracking in CMIP6 data, and finally generation of an atmospheric blocking climatology using MERRA2 data.

\subsection{Examples from the existing literature}

Since version 1.0, TE has been employed for feature tracking in a number of scientific studies. Here we catalogue known publications emerging from those studies, organized by feature type.

Tropical Cyclones (TCs). More than any other feature, TE has been employed for the study of TCs. TE was first employed as a TC tracker to understand intensity errors associated with one-way coupling between ocean and atmosphere in Zarzycki (2016). It was subsequently used to investigate the TC wind-pressure relationship in Chavas et al. (2017), a relationship later revisited in Moon et al. (2020) in which TE was used to assess its sensitivity to model resolution. In Wing et al. (2019), TE was applied to native grid data produced using the Community Atmosphere Model Spectral Element (CAM-SE) dynamical core to track TCs; outputs were then used to investigate the processes underlying moist intensification of TCs. A related study by Camargo et al. (2020) used this dataset to investigate the large-scale environment around TCs. In Roberts et al. (2020a) and Roberts et al. (2020b), TEderived TC tracks were used to understand resolution sensitivity and future change in both historical and future HighResMIP experiments (Haarsma et al., 2016) across several models. Along these lines, Balaguru et al. (2020) used TE to characterize TC climatology in the Energy Exascale Earth System Model (E3SM). Reed et al. $(2020,2021)$ used TE to extract tracks of hurricanes Florence (2018) and Dorian (2019) and attribute human influence on these storms. TE has also been used for tracking storms in aquaplanet simulations (Chavas and Reed, 2019) so as to better understand how dynamic forcing impacts TC genesis and size. Recent work by Stansfield et al. (2020) has also leveraged some of the more advanced capabilities in TE to filter fields (e.g., precipitation) in the vicinity of tracked features to evaluate model performance. TE has also been used for the tracking of TCs in extremely high-resolution regional simulations (Steptoe et al., 2021) and investigating TCs in paleoclimate simulations (Kiehl et al., 2021).

Extratropical Cyclones (ETCs). In order to better understand cyclonic storms and their impacts, Zarzycki et al. 


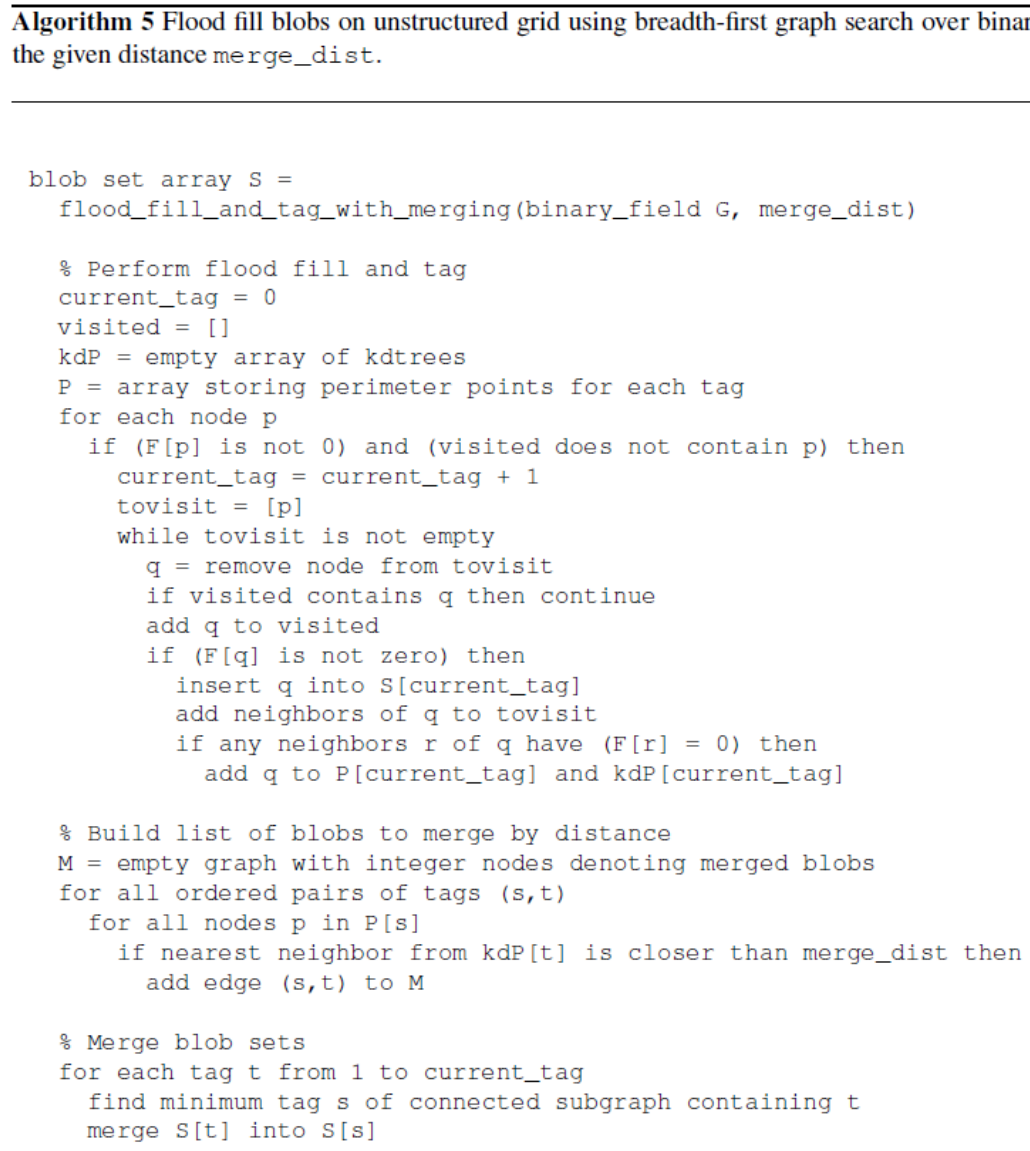

(2017) developed the ExTraTrack software framework atop TE to track TCs and ETCs through their entire life cycle. This module enabled cyclonic storms to be examined using the thermal wind and thermal asymmetry phase space of Hart (2003). ExTraTrack was later applied to a suite of highresolution global simulations in Michaelis and Lackmann (2019) and Michaelis and Lackmann (2021). ETCs were also tracked in the Community Earth System Model Large Ensemble (CESM-LENS) in Zarzycki (2018) to understand the drivers responsible for snowstorms in the US northeast. Then in Small et al. (2019), extratropical storms tracked using TE were used to determine if resolving ocean fronts improves the representation of simulated storm tracks. In Zhang et al. (2021) the vertical symmetry criterion from ExTraTrack was also adapted for the tracking of Mediterranean hurricanes (medicanes). Finally, TE was also used to track ETCs as part of an effort to evaluate severe local storm environments in climate models and reanalysis ( $\mathrm{Li}$ et al., 2020).

Monsoonal lows and depressions. Analogous to the study of Zarzycki and Ullrich (2017), Vishnu et al. (2020) optimized DetectNodes for the tracking of monsoon lows and depressions. A comprehensive analysis of input fields found that $850 \mathrm{hPa}$ streamfunction tended to produce better results compared with trackers based on sea level pressure, vorticity, and geopotential. A weighted critical success index (CSI) (Di Luca et al., 2015) was used to determine tracker performance. However, acknowledging the possibility of errors in the reference dataset (here the Sikka archive), the weighted CSI index used in this analysis also considered the degree to which a track is represented similarly across all reanalyses. A related study by Zhang et al. (2019) also tracked tropical depressions in the North Indian Ocean in 2018 to investigate the anthropogenic impact on this storm season, and a recent study by You and Ting (2021) used TE to assess trends in South Asian Monsoon low-pressure systems.

Atmospheric blocking. In Pinheiro et al. (2019), a suite of atmospheric blocking methods from TE were applied to ERA-Interim data to better understand sensitivities of atmospheric blocks to the detection algorithm and the meteorological environment around blocking features.

Atmospheric rivers (ARs). Atmospheric river tracking with TE was first documented as part of the Atmospheric River Transport Method Intercomparison Project (ARTMIP) in Shields et al. (2018) and later in Rutz et al. (2019). The proposed algorithm used the Laplacian of the integrated vapor transport (IVT) field rather than the IVT field itself, 


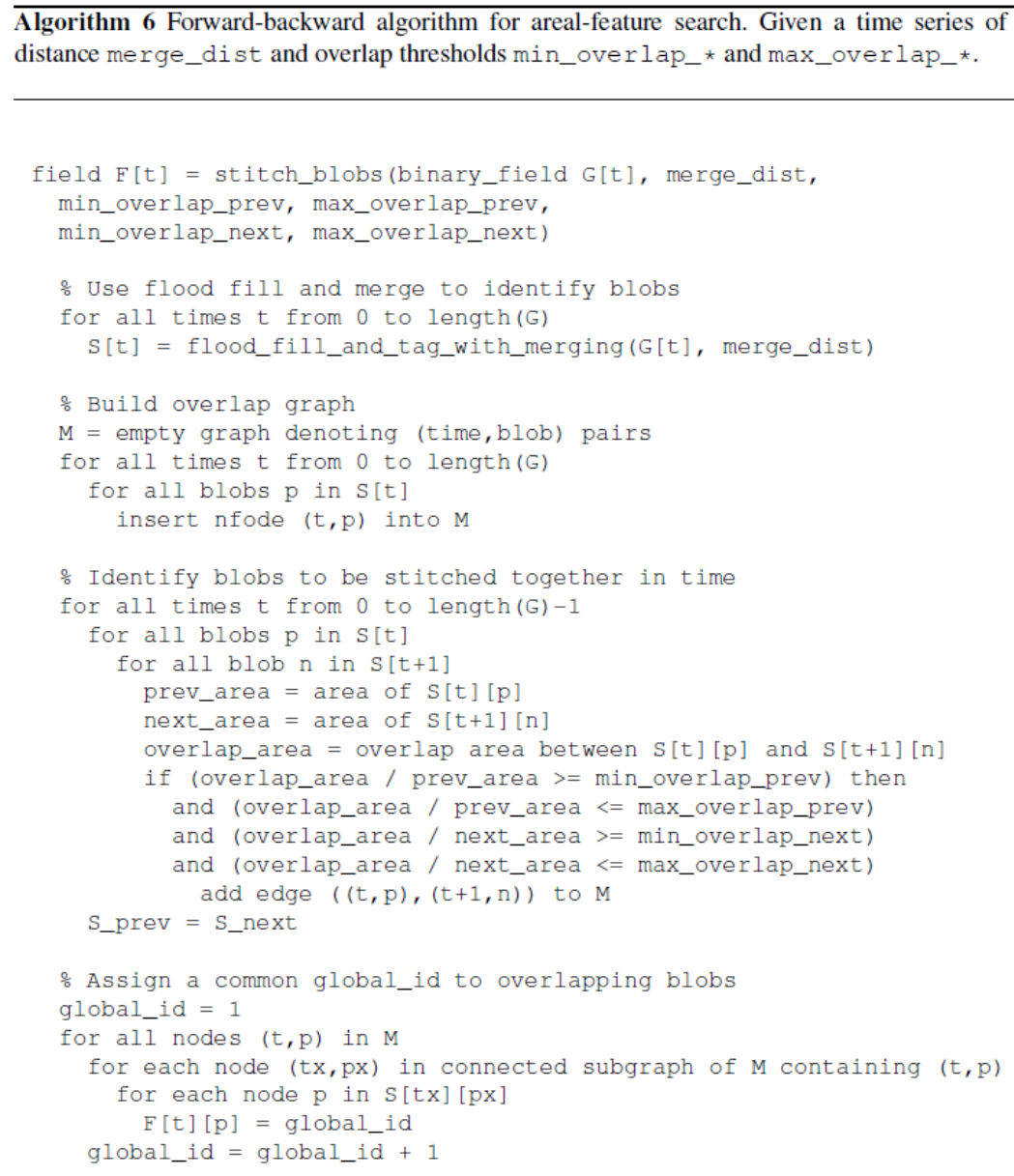

thus flagging IVT "ridges" rather than IVT over a threshold; this choice addressed issues of stationarity generally present in trackers using an IVT threshold. TE's algorithm has since been used both for AR detection and tracking (with DetectBlobs and StitchBlobs) in several subsequent studies (Rhoades et al., 2020b, a; Patricola et al., 2020; McClenny et al., 2020; Huang et al., 2021; Zhou et al., 2021).

\subsection{Tropical cyclone tracking in ERA5}

In Zarzycki and Ullrich (2017), a sensitivity analysis was carried out to optimize TE for the detection of tropical cyclones by benchmarking hit rate (HR) and false alarm rate (FAR) from reanalysis products against the International Best Track Archive for Climate Stewardship (IBTrACS; Knapp et al., 2010). The resulting configuration, which tracked storms based on sea level pressure minimum, produced the highest HR minus FAR differential in the literature across a wide range of reanalysis products. An interesting result that emerged from this analysis was that upper-level geopotential layer thickness (typically Z300 minus Z500) was the most robust indicator of an upper-level warm core across prod- ucts. In this section we apply the same configuration that provided maximal agreement between earlier-generation reanalyses and IBTrACS to ERA5 input (Hersbach et al., 2020) so as to identify ERA5 TC tracks.

\subsubsection{Step 1: identify candidate storms}

Tropical cyclone tracking is an exemplar of the MapReduce paradigm discussed earlier in this paper. Essentially all published algorithms for TC tracking (e.g., Ullrich and Zarzycki, 2017, their Appendix B) make use of a two-step process consisting of first detecting TC candidates, then stitching together candidates in time. Both steps of this process include hard thresholds that separate TCs from related features. Although TE allows users to vary the values of these thresholds, here we only consider one such variation of these parameters.

In the TC detection algorithm described in Zarzycki and Ullrich (2017), candidates are defined as points that have both a sea level pressure minimum and an upper-level warm core. These conditions are codified via the following command: 


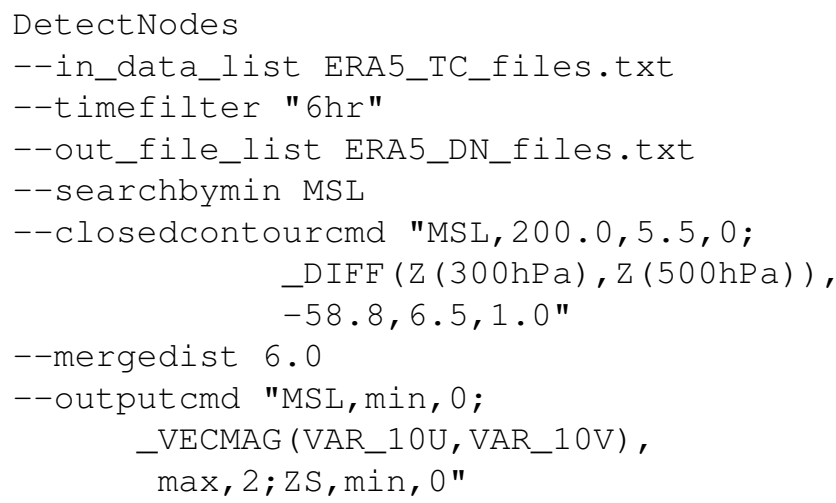

For this example, our ERA5 data come from the National Center for Atmospheric Research (NCAR) Research Data Archive (European Centre for Medium-Range Weather Forecasts, 2019), with 3D time-series data provided at hourly resolution in daily chunks, 2D time-series data provided at hourly resolution in monthly chunks, and 2D invariant data provided in a single file. The timefilter argument here indicates that data should be downselected to 6-hourly, which is typical for analyses of TCs. As different variables are distributed across multiple files, the first two lines of the input data consist of several files containing 3D geopotential height on pressure surfaces (Z), 2D mean sea level pressure (MSL), 2D $10 \mathrm{~m}$ zonal and meridional wind speeds (VAR_10U and VAR_10V), and surface elevation (ZS), separated by semicolons. Note that TE supports different agglomerations of time slices as it uses the CF-compliant time to match time slices across files.

To first limit the search space of possible TCs, we identify candidates as local minima in the sea level pressure field. Two closed contour criteria are used to eliminate candidates. As argued in Ullrich and Zarzycki (2017), closed contour criteria are a more physically grounded way of defining features since they can be employed for both discrete and continuous fields - as opposed to, for example, "grid point maxima" that are inherently sensitive to the dataset's grid structure and spacing. The first criterion we use for TCs is "MSL, $200.0,5.5,0$ ", which indicates that mean sea level pressure must increase by $200 \mathrm{~Pa}$ over a $5.5^{\circ}$ great circle distance (GCD) from the candidate point (the low-pressure region must be of sufficient magnitude and sufficiently compact to be considered coherent). The second criterion is "_DIFF ( $\mathrm{Z}(30 \mathrm{hPa}), \mathrm{Z}(50 \mathrm{hPa}))$, $-58.8,6.5,1.0$ ", which indicates that the difference between geopotential (Z) on the 300 and $500 \mathrm{hPa}$ surfaces must decrease by $58.8 \mathrm{~m}^{2} \mathrm{~s}^{-2}$ (equal to $6 \mathrm{~m}$ geopotential height) over a $6.5^{\circ} \mathrm{GCD}$, using the maximum value of this field within $1^{\circ} \mathrm{GCD}$ as reference. This second criterion indicates that there must be a coherent upper-level warm core attached to the local low so as to structurally differentiate these features from extratropical systems. It is also an example of TE's ability to evaluate functions of meteorological fields at runtime. Finally, candidates that have been identified with this protocol are eliminated if a stronger minimum exists within $6^{\circ} \mathrm{GCD}$

The remaining argument outputcmd indicates three additional outputs that are calculated and written as additional columns in each nodefile. Here "MSL, min, 0 " outputs the value of MSL at the candidate point, “_VECMAG (VAR_10U, VAR_10V), max, 2" outputs the maximum magnitude of the vector wind at $10 \mathrm{~m}$ altitude within $2^{\circ} \mathrm{GCD}$ of the candidate, and " $\mathrm{ZS}, \mathrm{min}, 0$ " outputs the surface height at the candidate point. These variables are needed in the subsequent StitchNodes step to construct and filter TC trajectories.

\subsubsection{Step 2: connect candidate storms in time}

Once TC candidates have been identified on each time slice, the "stitching" step in the algorithm ties these candidates together in time to form TC trajectories (the "Reduce" operation in the MapReduce paradigm). Some features that are too weak, too short-lived, or too disorganized are eliminated from contention at this stage. Also, features that are more likely related to topographic anomalies rather than real storms are also removed.

To build these trajectories with TE, we apply the StitchNodes command to the output from step 1:

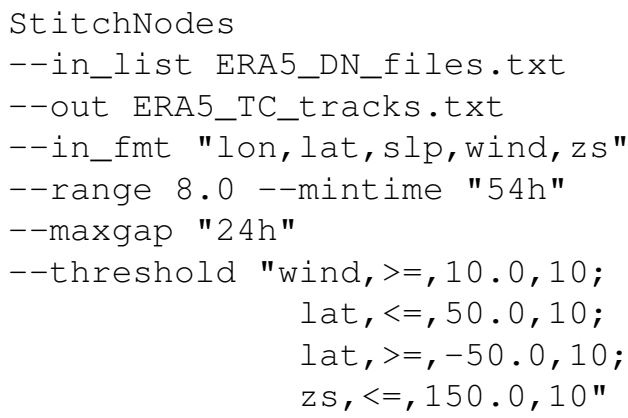

The first three arguments here indicate the input candidate nodefile (produced by DetectNodes) and the output nodefile. The format of these files differ because they convey different information - the former containing candidates detected at each time slice, and the latter containing paths or lists of candidates from different time slices. Nonetheless, auxiliary candidate information computed with DetectNodes' output cmo is preserved.

The relevant tuning parameters are specified by range, mintime, and maxgap and refer to the maximum distance (in ${ }^{\circ} \mathrm{GCD}$ ) that a feature can move between subsequent detections, the minimum persistence time of each trajectory (calculated as the time between initiation and termination), and the maximum duration between two sequential detections, respectively. In particular, maxgap is a novel option that allows a path to be missing candidates for some time slices (for instance due to temporary weakening of a TC as it passes over land). 


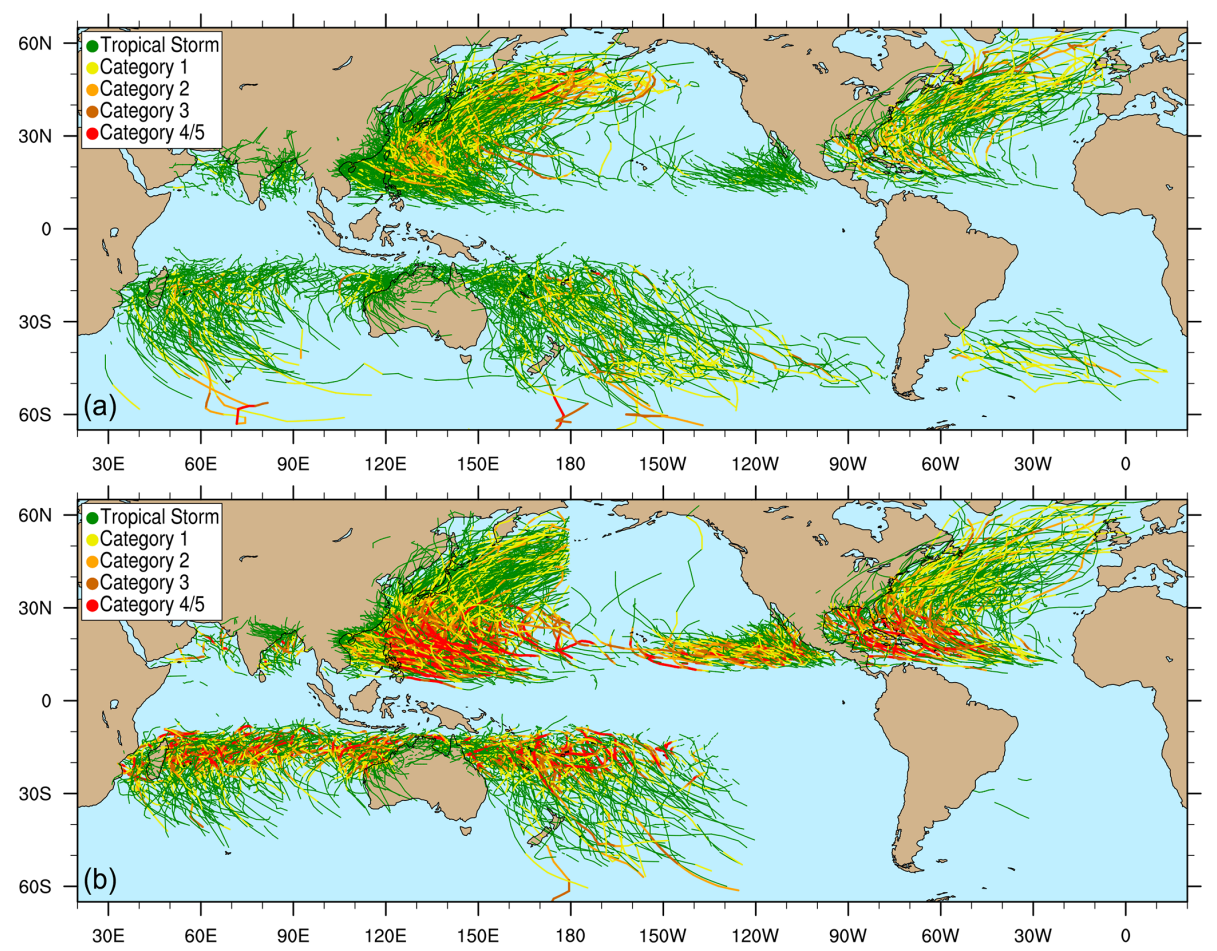

Figure 2. Tropical cyclone trajectories from ERA5 (a) and IBTrACS (b) over the period 1980-2019, inclusive. TempestExtremes is used to track TCs in ERA5, while pointwise observations are used for IBTrACS. Coloring denotes the instantaneous Saffir-Simpson category of the tropical cyclone. The categories are computed from sea level pressure and applying the pressure-wind relationship of Atkinson and Holliday (1977) with updated coefficients from Knaff and Zehr (2007). The discontinuity at $180^{\circ}$ longitude in the bottom panel is due to historical forecast center responsibilities.

Four field-dependent thresholds are then specified for a trajectory to be accepted. The first threshold "wind, $>=, 10.0,10$ " indicates that the wind magnitude (derived from the "wind" column in the nodefile) must be greater than $10 \mathrm{~m} \mathrm{~s}^{-1}$ for at least 10 time slices; this ensures that these features are sufficiently intense to be classified as tropical storms. The next two thresholds "lat, $<=, 50.0,10$; lat, $>=,-50.0,10$ " indicate that the latitude of the feature must be between $50^{\circ} \mathrm{S}$ and $50^{\circ} \mathrm{N}$ for at least 10 time slices, so as to eliminate any extratropical features that could not have existed as tropical storms. The final threshold " $z \mathrm{~s},<=, 150.0,10$ " indicates that the feature must exist at an elevation below $150 \mathrm{~m}$ for at least 10 time slices; this removes false alarms that can often appear in regions of rough topography that are associated with the sea level pressure correction.

\subsubsection{Results from the generation of tropical cyclone trajectories}

Figure 2 depicts the tropical cyclone trajectories produced from this analysis in ERA5, along with IBTrACS over the same period for reference. Storms are color-coded by sea level pressure, as opposed to surface winds, since it has been found that the former is better resolved in coarser datasets (Chavas et al., 2017). With that said, this procedure may overestimate storm intensity at higher latitudes where storms are beginning to undergo extratropical transition. While tracked storms in ERA5 are generally too weak in aggregate (lower density of orange and red trajectories in top panel), a common problem amongst reanalyses (Schenkel and Hart, 2012; Murakami, 2014; Hodges et al., 2017), the method shows a high spatial and temporal correlation of storm climatology when compared to pointwise observations, and it produces superior hit rates $(78 \%$ for all TCs and $95 \%$ for those with wind speeds exceeding $33 \mathrm{~m} \mathrm{~s}^{-1}$ ) and false alarm ratios (14\% globally) when compared to many legacy tracking techniques (Zarzycki et al., 2021).

The TC detector described in this section was run on the NERSC Cori supercomputer on one node and using 32 threads. When run over the ERA5 data from January 1979 through February 2020 at 6-hourly temporal resolution, with 15035 daily files, DetectNodes required $140 \mathrm{~min}$ run time. DetectNodes on Cori is strongly I/O bound, with reads from NetCDF files responsible for $81 \%$ of the total runtime. StitchNodes required 4 min and $55 \mathrm{~s}$ to process all 15035 outputs from DetectNodes. 


\subsection{Fractional contribution of precipitation from TCs}

For the examples here, we calculate the fractional contribution of precipitation from TCs for one reanalysis dataset, ERA5, and one observational dataset, the Tropical Rainfall Measuring Mission (TRMM3B42; Huffman et al., 2007). For ERA5, the TC track files are created as described in Sect. 3.2. For TRMM, the IBTrACS dataset is used for TC track observations. Because there are limited comprehensive and long-term observational datasets of complete TC wind fields, ERA5 wind field data are combined with IBTrACS to calculate the outer radius at every time step for all historical TC tracks for the TRMM analysis.

\subsubsection{Step 1: compute the outer radius of each tracked TC}

As argued by Schenkel et al. (2017), the largest radius outside of the eyewall where the azimuthally averaged wind speed exceeds $8 \mathrm{~m} \mathrm{~s}^{-1}$ (r8) tends to be a good measure of the size of a TC. In Stansfield et al. (2020), TE was used to examine the distribution of $\mathrm{r} 8$ among TCs in reanalysis data in ERA5 and a series of runs with the Community Earth System Model (CESM). They further compared and contrasted TC-related precipitation within $\mathrm{r} 8$ against precipitation within a fixed distance of $500 \mathrm{~km}$. We thus follow Stansfield et al. (2020) and use $\mathrm{r} 8$ as our criterion for grid points to be part of the TC.

To begin, radial profiles and radius of $8 \mathrm{~m} \mathrm{~s}^{-1}$ wind are added to the nodefile generated in Sect. 3.2.2 and the IBTrACS nodefile (not shown):

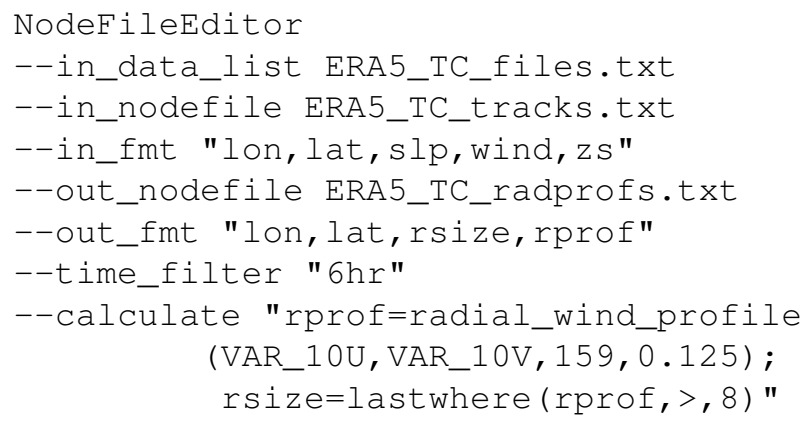

The input to this operation includes the files containing the 2D ERA5 $10 \mathrm{~m}$ zonal and meridional wind speeds (VAR_10U and VAR_10V) and the nodefile generated in Sect. 3.2.2. As part of this analysis we also augment an IBTrACS nodefile in a similar manner, using the IBTrACS TC tracks but ERA5 winds to estimate TC size (command not shown here). As in Sect. 3.2.1, a time filter is used to only analyze 6-hourly time slices of data. Internal to the execution of this command is the construction of a date object for each entry of the nodefile which is then cross-referenced against every time slice in the list of data files to find the corresponding field - in this way indexing is abstracted from the user.
The calculations requested from NodeFileEditor are specified by the calculate argument, executed from left to right. First the radial profile is computed with radial_wind_profile (VAR_10U, VAR_10V, 159,0.125) and stored in variable rprof. These arguments indicate which variables should be used for the calculation and that the radial profile should consist of 159 bins of width $0.125^{\circ} \mathrm{GCD}$. After the radial profile is calculated, the last value where the radial wind profile is greater than $8 \mathrm{~m} \mathrm{~s}^{-1}$ is located and written to the nodefile. The last value in the array is taken because we want to avoid recording the radius of the $8 \mathrm{~m} \mathrm{~s}^{-1}$ wind within the TC inner core. The number of bins and the bin width were chosen based on the horizontal grid spacing of the ERA5 wind data, which is approximately $31 \mathrm{~km}$. The bin width of $0.125^{\circ}$ adequately samples points at this grid spacing to create the radial wind profiles. The number of bins ensures the radial averaging extended out far enough from the TC center points to capture the storms' complete wind circulations.

\subsubsection{Step 2: build a mask using the outer radius of the storm}

With the $\mathrm{r} 8$ value for each TC now in hand, we define "TCrelated precipitation" as any precipitation which occurs at grid points that are considered part of a TC. Employing TE's NodeFileFilter command, precipitation outside of the circle with radius $\mathrm{r} 8$ centered on each TC is set to zero:

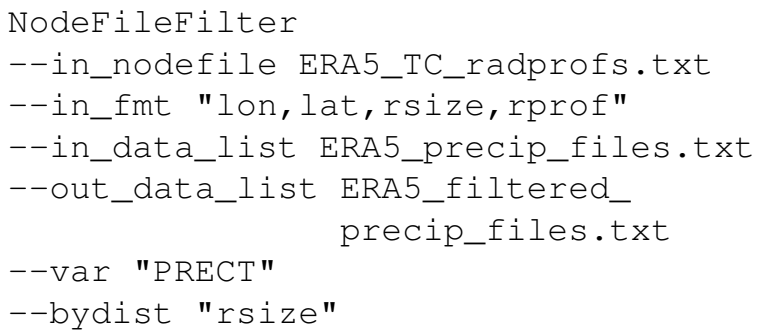

The input nodefile is the output nodefile from NodeFileEditor, now augmented with the radius of $8 \mathrm{~m} \mathrm{~s}^{-1}$ winds. The input data contain 6-hourly ERA5 precipitation data from the NCAR Research Data Archive (European Centre for Medium-Range Weather Forecasts, 2019) under variable name PRECT. Precipitation in ERA5 is calculated from hourly forecasts initialized from the analysis at 06:00 and 18:00 UTC. Precipitation is converted from hourly to 6hourly by adding up the accumulated precipitation $3 \mathrm{~h}$ before and $3 \mathrm{~h}$ after the desired time steps of 00:00, 06:00, 12:00, and 18:00 UTC. For example, to calculate 6-hourly precipitation at 06:00 UTC, the precipitation from 03:00 to 09:00 UTC is added up. For the TRMM analysis, the TRMM precipitation data are originally 3-hourly, so before analysis the TRMM data are summed into 6-hourly data. This is done using a centered averaging method; so, for example, to calculate 6-hourly precipitation at 06:00 UTC, half of the 
03:00 UTC precipitation, all of the 06:00 UTC precipitation, and half of the 09:00 UTC precipitation are added up. Output consists of a sequence of NetCDF files, one for each input file, containing filtered precipitation.

The final argument specifies how the filtering is performed, in this case by distance using rsize. This procedure only keeps precipitation grid point values that are within this distance of each detected TC. Internally to NodeFileFilter, the mask is computed by employing a k-d tree (see discussion in Ullrich and Zarzycki, 2017).

\subsubsection{Results from the generated tropical cyclone precipitation climatology}

Figure 3 shows the relative contribution to global precipitation from TCs for ERA5 and TRMM, calculated by using NCO's (NetCDF Operator) ncra to sum up the TC precipitation within $\mathrm{r} 8$ filtered by NodeFileFilter and dividing it by the sum of the total precipitation over the entire length of the datasets (1985-2019 for ERA5 and 1998-2014 for TRMM). The areas of largest TC contribution align with the areas of the highest TC activity shown in Fig. 2 and typically occur over the ocean, in broad agreement with Prat and Nelson (2013). Khouakhi et al. (2017) (their Fig. 3b) made a similar plot, except using land-based gauge data and for a slightly different time period, and showed similar locations of maximum contributions of $40 \%-50 \%$ over northwestern Australia and eastern Asia.

\subsection{Extratropical cyclones}

Extratropical cyclones are midlatitude, synoptic-scale weather features responsible for a host of impacts, including high winds, coastal surge, and heavy precipitation, which can fall as rain, snow, sleet, or freezing rain (Schultz et al., 2019; Dacre, 2020). Even though these features occur at relatively large spatial scales, models still have difficulty in capturing hazards related to ETCs (e.g., Colle et al., 2015; Catalano et al., 2019), emphasizing the importance of evaluating them at a process level in weather and climate datasets.

Here we produce 2D composites of several fields associated with ETCs tracked in the first historical member of the Community Earth System Large Ensemble (Kay et al., 2015). ETCs over the northeastern United States were originally analyzed in this dataset in Zarzycki (2018). The years available for analysis in the historical simulations range from 1990 to 2015, inclusive. We also apply a pre-defined intensity threshold and spatially constrain ETCs to pass over the continental United States (CONUS) in order to demonstrate a regional analysis and highlight both the filtering and compositing capabilities of TE.

\subsubsection{Step 1: generate extratropical cyclone trajectories}

The algorithm applied here identifies cyclonic storms as sea level pressure minima. To avoid topographic lows and features that are not meteorological in character, additional criteria are imposed on the minimum lifetime and propagation distance. Note that while the algorithm is highly similar to that published in Zarzycki (2018), other ETC detection algorithms analogous to those published in the Intercomparison of Mid-Latitude Storm Diagnostics (IMILAST; Neu et al., 2013) can be configured using TE's command line options. These alternative approaches include tracking on low-level geopotential height minima or vorticity maxima, filtering based on spatial gradients, and removing candidate storms over higher terrain (see Table 1 in Neu et al., 2013). Also, while a more complex algorithm could help eliminate cyclones that are tropical in nature (e.g., by using the no_closed_contour argument to eliminate candidates with an upper-level warm core), none is applied here due to the relatively low resolution of CESM LENS. These coarser grid spacings are generally insufficient to resolve TCs (Walsh et al., 2015), although higher-resolution evaluations of ETCs may require additional exclusionary thresholds to minimize their inclusion in storm track datasets if desired.

To begin, cyclonic storms are identified using Detect $N$ odes by following sea level pressure (here, PSL) minima in 6-hourly data:

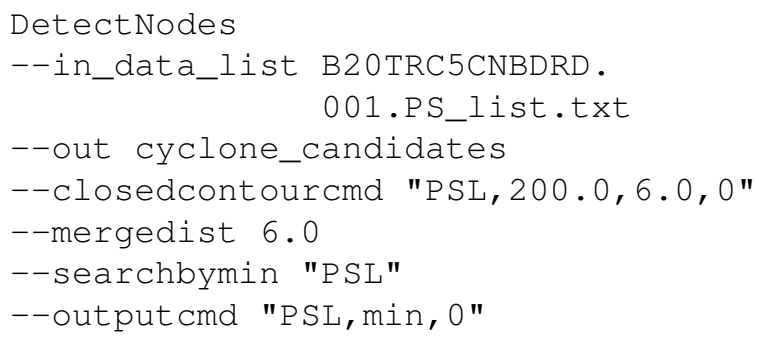

Our criterion for cyclonic storms is that the minimum pressure must be enclosed by a closed contour of $200 \mathrm{~Pa}$ within $6.0^{\circ}$ of cyclone center. This minimum pressure location also defines the cyclone center. Candidates within $6.0^{\circ}$ of one another are merged, with the lower pressure taking precedence. Outputs from DetectNodes are then concatenated into a single candidate list, and StitchNodes is run to track these features in time:

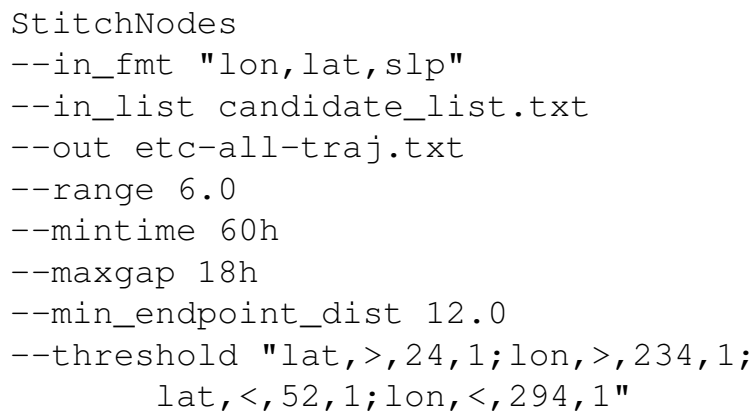



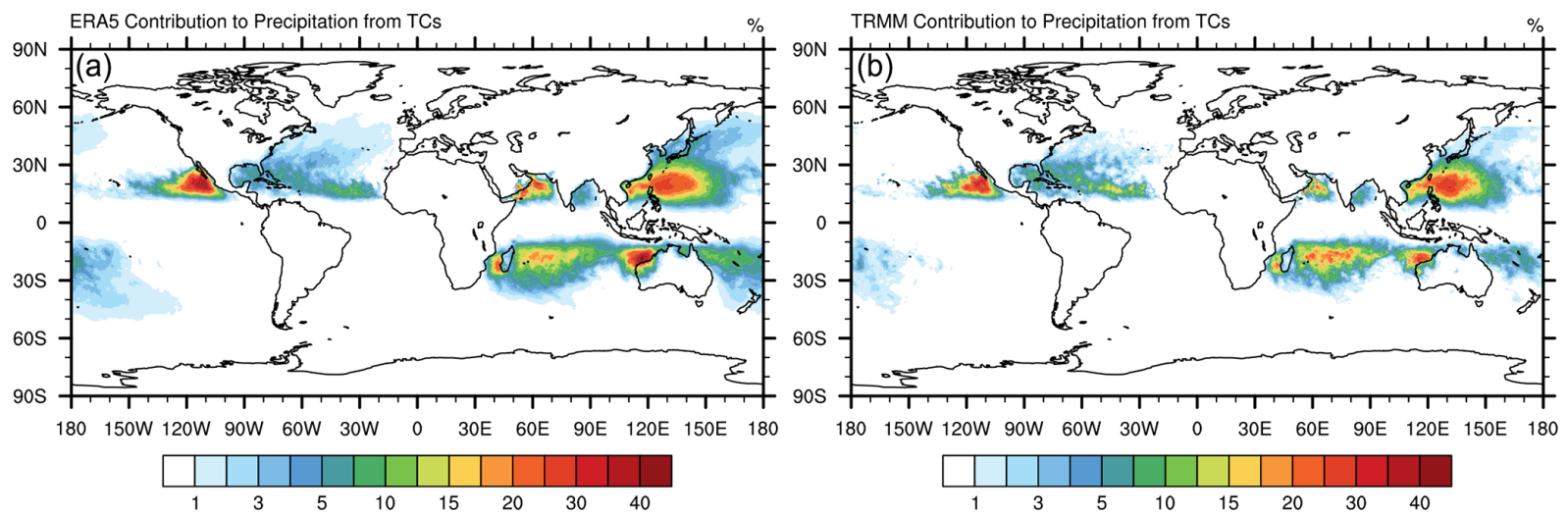

Figure 3. Percent contribution to precipitation from tropical cyclones using precipitation field from (a) ERA5 and (b) TRMM.

Annual ETC track density (all)

(a)

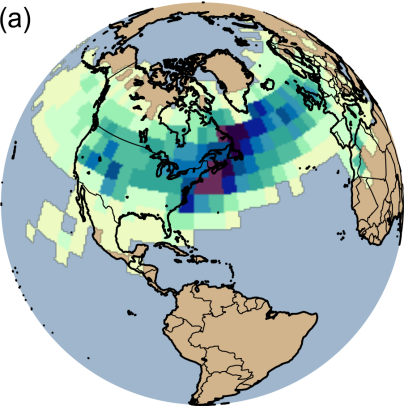

$6 \mathrm{~h} \mathrm{ETC} \mathrm{fix} \mathrm{per} 5^{\circ} \times 5^{\circ}$ box per year

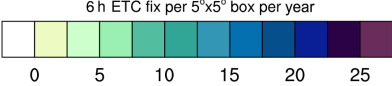

Annual ETC track density $(<=990 \mathrm{hPa})$

(b)

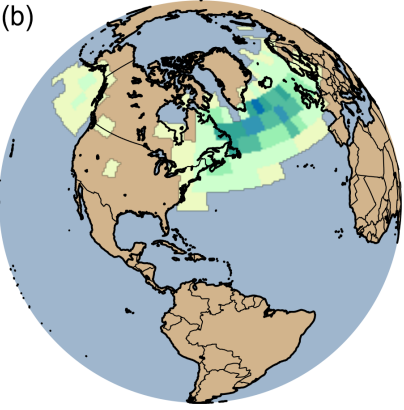

$6 \mathrm{~h} \mathrm{ETC} \mathrm{fix} \mathrm{per} 5^{\circ} \times 5^{\circ}$ box per year

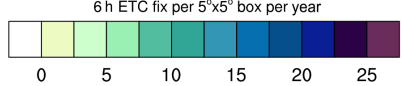

Figure 4. Track density maps for all CONUS ETCs tracked in the first historical member of CESM LENS (a) and only ETCs with simulated SLP less than or equal to $990 \mathrm{hPa}(\mathbf{b})$. Units are number of 6-hourly ETC occurrences per $5^{\circ} \times 5^{\circ}$ grid box per year.

Here the StitchNodes thresholds require that storms persist for at least $60 \mathrm{~h}$, with a maximum gap (time between sequential detections satisfying the DetectNodes criteria) of at most $18 \mathrm{~h}$. Furthermore, at least one point must pass through a geographic region (representing CONUS) bounded by 24 and $52^{\circ} \mathrm{N}$ latitude and 234 and $294^{\circ} \mathrm{E}$ longitude. We also require ETCs move at least $12^{\circ} \mathrm{GCD}$ from the start to the end of the trajectory, as specified by the min_endpoint_dist argument, in order to eliminate stationary features (e.g., the Icelandic Low) and spurious shallow lows generated over regions of high topography.

\subsubsection{Step 2: filter out ETCs with sea level pressure above $990 \mathrm{hPa}$}

In some cases, it may be desirable to filter out the more intense, potentially more impactful events. While the definition of a strong ETC is inherently subjective, we define a central pressure of $990 \mathrm{hPa}$ as the demarcation between strong and moderate/weak ETCs as in Zhang and Colle (2017). To do so, all ETCs tracked in step 1 are passed into NodeFileEditor, in which a new trajectory file specified by argument out_nodefile is generated with storms only possessing intensities of $990 \mathrm{hPa}$ or lower:

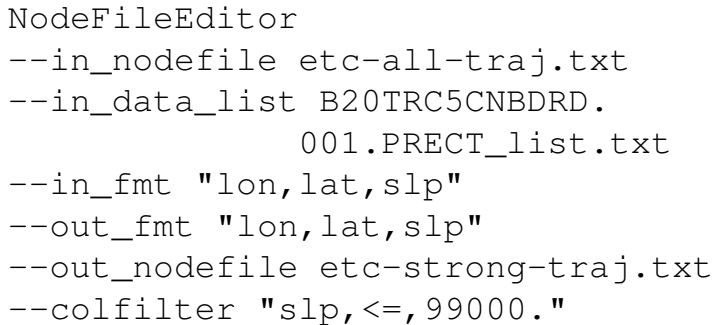

Figure 4 shows the annual track density of all ETCs tracked in step 1 (left) and the same plot but with only the subset of ETCs stronger than $990 \mathrm{hPa}$ included (right). These results broadly match those of other ETC trackers depicted in Fig. 1 of Neu et al. (2013), with a storm track belt extending across the North Atlantic centered on approximately $40-60^{\circ} \mathrm{N}$ latitude.

\subsubsection{Step 3: filter data within $25^{\circ}$ of storm center and composite}

Corresponding precipitation rate outputs from the same ensemble member are masked within $25^{\circ} \mathrm{GCD}$ of a storm center tracked in step 1 . Here, all precipitation associated with the cyclone is retained, while all precipitation not within $25^{\circ}$ of a storm is set to zero.

To extract spatial information associated with ETCs we first filter a spatiotemporally continuous gridded dataset using NodeFileFilter:

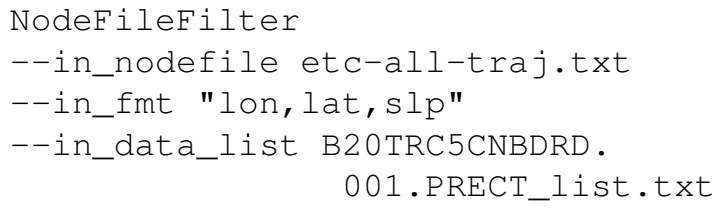



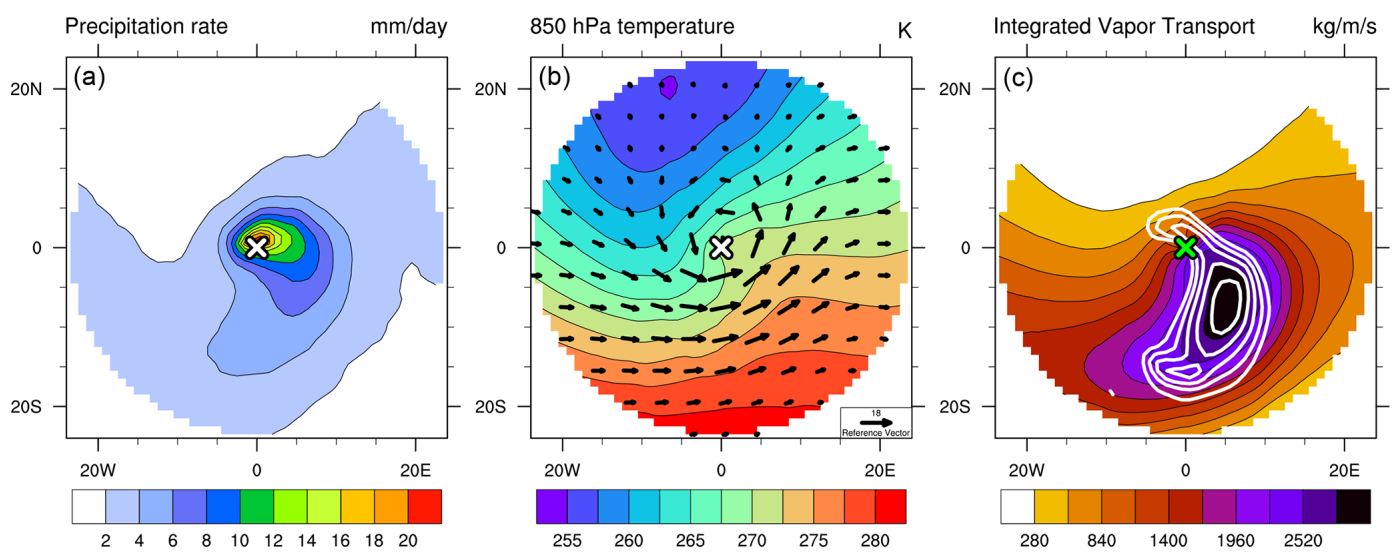

Figure 5. Composites of meteorological quantities centered on ETC storm center of all filtered storms with SLP less than or equal to $990 \mathrm{hPa}$ in the first CESM-LENS historical member. Shown from left to right are precipitation rate $\left(\mathrm{mm} \mathrm{d}^{-1}\right), 850 \mathrm{hPa}$ temperature (K) with overlain $850 \mathrm{hPa}$ wind vectors $\left(\mathrm{m} \mathrm{s}^{-1}\right)$, and integrated vapor transport $\left(\mathrm{g} \mathrm{kg}^{-1}\right)$ with overlain $600 \mathrm{hPa}$ pressure velocity (omega) contours (every $\mathrm{hPah}^{-1}$ starting at $\left.-2 \mathrm{hPah}^{-1}\right)$. Each composite includes 11164 data points.

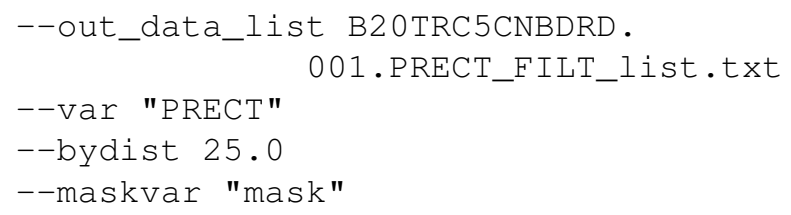

A binary variable named "mask" (as specified by argument maskvar) is also included in the filtered files for reference and can be used for offline masking and visualization.

As a last step, storm-centered composites are generated using the following command:

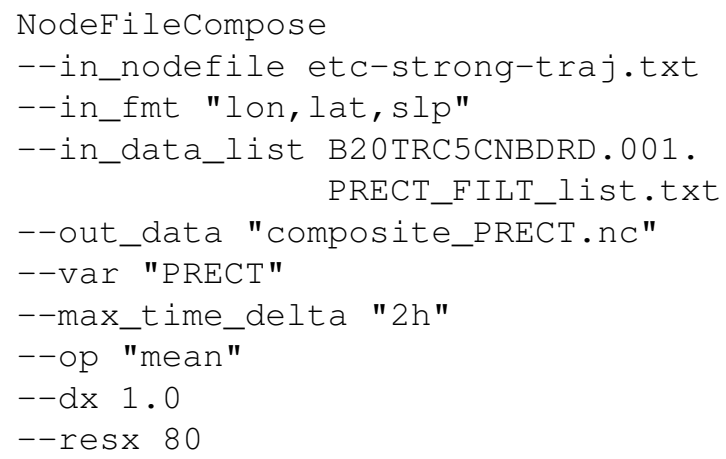

Here, only ETCs filtered above to have central SLP values below $990 \mathrm{hPa}$ are composited. Although we can composite any 2D field, here we apply the compositing tool to precipitation filtered by NodeFileFilter. The argument max_time_delta indicates that the data slice nearest in time to the tracked feature (within $2 \mathrm{~h}$ ) should be composited - this is useful when the discrete times from data and features are not exactly aligned. The arithmetic mean is calculated centered on the storm location (see Sect. 2.4). The resulting stereographic composite has a grid spacing of $1^{\circ}$ and a resolution of $80 \times 80$ grid points.

\subsubsection{Results from compositing extratropical cyclone fields}

Figure 5 shows the composited precipitation rate field (PRECT), along with analogously calculated composites of $850 \mathrm{hPa}$ temperature (T850) and integrated vapor transport (IVT). Total precipitation is largest near the storm center. Further, advection of warm, moist air wrapping cyclonically around the eastern side of the storm center is seen in the $850 \mathrm{hPa}$ temperature field (composite wind vectors shown in black). Lastly, the collocation of high values of IVT and rising motion in the mid-troposphere $(600 \mathrm{hPa}$ omega contours shown in white) shows strong upward and poleward moisture advection associated with the warm conveyor belt, as previously shown in hand-compositing studies (e.g., Browning, 1986; Field and Wood, 2007).

\subsection{Atmospheric rivers}

Atmospheric rivers (ARs) are thin and long filamentary structures characterized by high integrated vapor transport (IVT; Payne et al., 2020). As found by Zhu and Newell (1998), ARs are responsible for approximately $90 \%$ of poleward vapor transport. Our goal in this section is to reproduce this result in 20 years of ERA5 reanalysis using the Tempest AR detection algorithm (Shields et al., 2018; Rhoades et al., 2020b, a; McClenny et al., 2020).

\subsubsection{Step 1: detect ridges in the IVT field}

As described in McClenny et al. (2020), the Tempest AR detection algorithm detects ARs as ridges in the IVT field, where IVT is defined pointwise as

$I V T=\sqrt{V I W V E^{2}+V I W V N^{2}}$. 
Here we have adopted the nomenclature of ERA5 for vertically integrated eastward vapor transport (VIWVE) and northward vapor transport (VIWVN). Ridge points are associated with high downward curvature and identified as those points where the Laplacian of the IVT field is below a fixed threshold (here chosen to be $-2 \times 10^{4} \mathrm{~kg} \mathrm{~m}^{-2} \mathrm{~s}^{-1} \mathrm{rad}^{-2}$ ). These points are useful indicators of the presence of ARs because this threshold identifies either long and narrow features or localized maxima (which are subsequently filtered using a minimum area criterion). Here the Laplacian is calculated using eight radial points at a $10^{\circ} \mathrm{GCD}$ (as described in Appendix B); this large stencil on the Laplacian provides some smoothing of the field. Note that all field manipulation routines are handled by TE internally. The command for this operation is as follows:

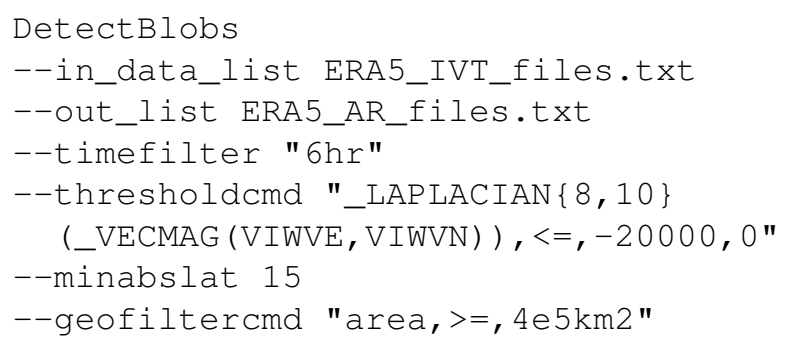

The first three arguments refer to the list of input files and output files and specify that data should be downsampled to 6-hourly time steps. The grid-point-level filtering operation is specified via the thresholdcmd argument, which uses the gridded data processor kernel built into TE to internally process the eastward and northward components of the integrated vapor transport (VIWVE and VIWVN, respectively) during the tagging operation. Specifically, the operation specified here identifies candidate grid points using a threshold on the Laplacian of the IVT. This command first calculates IVT using the vector magnitude operator and then calculates the Laplacian of the resulting field. Only points whose Laplacian is less than the threshold are retained. The last two arguments are then used to remove features too near the Equator and those that are deemed too small: the latitude of each tagged grid point must be at least $15^{\circ}$, and each blob must have a minimum area of $4 \times 10^{5} \mathrm{~km}^{2}$. Such filtering criteria are typical for AR trackers (Shields et al., 2018).

\subsubsection{Step 2: filter out tropical cyclones}

As noted in McClenny et al. (2020), tropical cyclones, which also tend to exhibit large values of IVT, are sometimes picked up as part of the detection procedure. Although their contribution to poleward IVT is small, it is nonetheless desirable to exclude TCs from this calculation. This can be done using the ERA5 TC tracks produced in Sect. 3.2 to filter out points within a prescribed distance of each detected TC:

NodeFileFilter

--in_nodefile ERA5_TC_tracks.txt

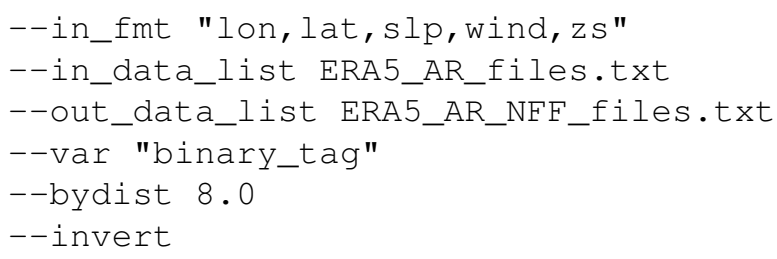

Here the nodefile from ERA5 is specified by in_nodefile and in_fmt. The input list of files containing the AR binary masks, specified with in_data_list, is the same as the output from DetectBlobs. The filtered output files are written to the file specified by out_data_list. The last two arguments here are key to the filtering procedure, specifying that the mask should include all points except those within $8^{\circ} \mathrm{GCD}$ of each nodal feature.

Figure 6 shows the ERA5 IVT field on 25 September 2019 at 18:00 UTC, along with the outlines of AR objects detected using TE. On this date, an AR event was responsible for flooding in California's Russian River basin (seen here intersecting the US west coast). Dashed lines in this plot show the footprint of Super Typhoon Wutip at $15^{\circ} \mathrm{N}, 139.75^{\circ} \mathrm{E}$ and Tropical Cyclone Pola at $14^{\circ} \mathrm{S}, 175.5^{\circ} \mathrm{W}$, both of which have been excluded from the AR mask. Notably, Pola does not appear in IBTrACS until 26 February 2019 at 06:00:00 UTC.

\subsubsection{Step 3: apply AR mask to northward vapor transport field}

To now investigate AR and non-AR poleward moisture transport, we apply the mask generated in step 2 to the VIWVN field (northward vapor transport). Here we leverage the VariableProcessor executable, which allows us to apply TE's built-in operations on a set of input files. Here the input file ERA5_VPIN.txt is the same as ERA5_AR_NFF_files.txt, except with the corresponding ERA5 VIWVN file appended to each line. To perform the processing we apply the following command:

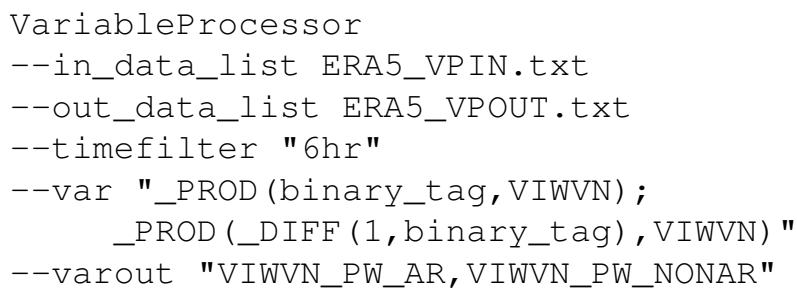

The var argument here is specified to leverage TE's internal gridded variable processor. Since binary_tag only has value 0 or 1 , the product of VIWVN and binary_tag will capture points within ARs, whereas the product of VIWVN and_DIFF (1, binary_tag) will capture points not within ARs. These two variables are then written as VIWVN_AR and VIWVN_NONAR in the output file.

Once AR and non-AR northward IVT have been calculated on a grid point level, the final processing step is handled outside of TE. To do so we take the time average and 

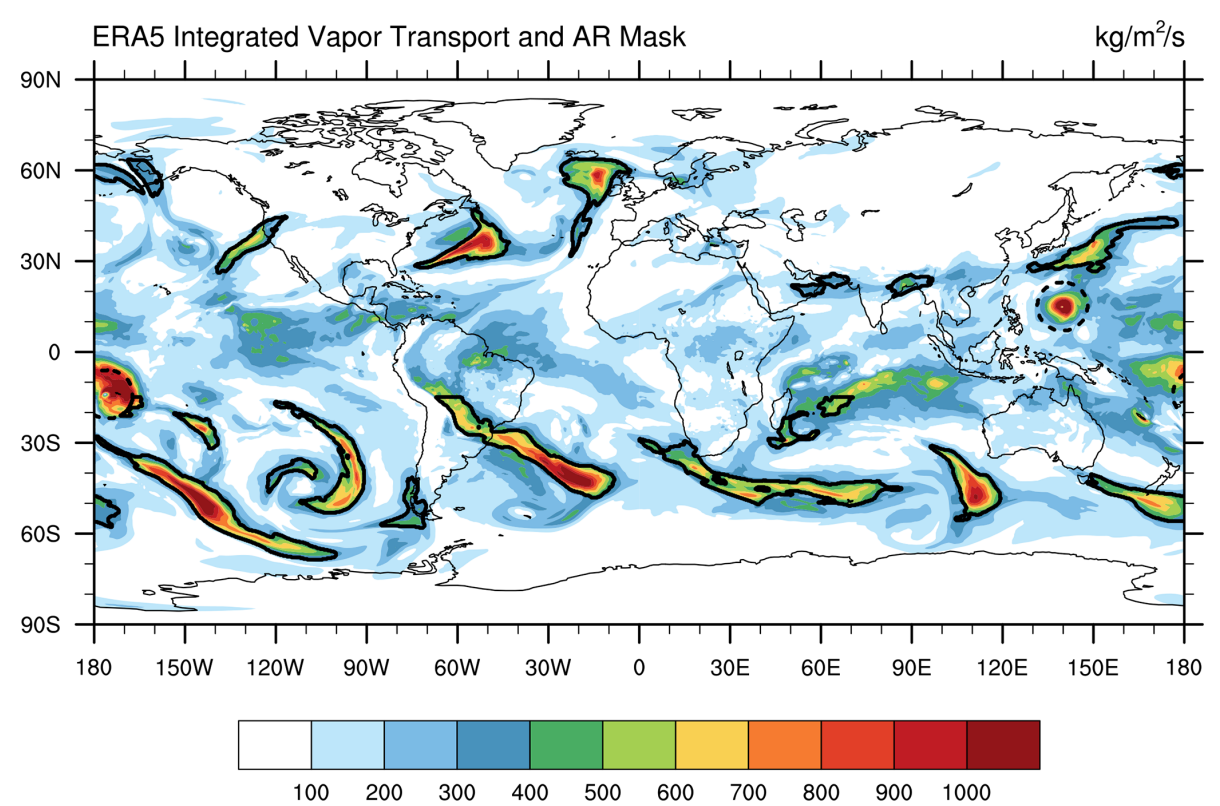

Figure 6. ERA5 integrated vapor transport (IVT) field with AR mask (black outlines) from 25 September 2019 18:00 UTC. Tropical cyclones that have been filtered from the AR mask are indicated with dashed black lines ( $8^{\circ}$ radius GCD).

zonal average of the fields produced by VariableProcessor using NCO's robust record averaging (ncra) and weighted averaging (ncwa) operators.

\subsubsection{Results from calculation of northward vapor transport from $A R$ and non-AR points}

Figure 7 shows zonal mean northward IVT for AR and nonAR points (top row), along with the relative contribution to northward IVT from ARs (bottom row). Note that because it is a fractional quantity, the bottom row equivalently shows fractional contribution to poleward IVT. The top row here is complementary to Fig. 14 (middle) in Rutz et al. (2019), which was computed with 6-hourly MERRA2 data. The agreement between these two results is reassuring and confirms that the AR tracker employed in this section is consistent with other trackers. In the lower figure we see that the AR contribution to poleward transport around $45^{\circ} \mathrm{N}$ and $45^{\circ} \mathrm{S}$ is indeed close to the $90 \%$ value reported by Zhu and Newell (1998), although this contribution then decays precipitously at more poleward latitudes. Note, however, that this is in part because AR moisture transport is almost always poleward, whereas non-AR transport is a mix of both poleward and equatorward contributions.

The AR detector described in this section was run on the NERSC Cori supercomputer on two nodes with 32 threads per node (64 threads total). When run over the ERA5 monthly data from January 1979 through February 2020 at 6-hourly temporal resolution with 494 monthly files, DetectBlobs required $34 \mathrm{~min}$ and $42 \mathrm{~s}$. Again this run was largely I/O bound, with $66 \%$ of the total run time from file input. Ap- proximately $13 \%$ of the total run time is spent applying the Laplacian operator, while $6 \%$ ( $2 \mathrm{~min}$ and $10 \mathrm{~s}$ ) is spent constructing the Laplacian. Again using 64 threads, NodeFileFilter required $50 \mathrm{~s}$, while VariableProcessor required $14 \mathrm{~min}$ and $14 \mathrm{~s}$.

\subsection{Atmospheric blocking}

Our final example addresses the development of a climatology of atmospheric blocking frequency. Atmospheric blocking events are synoptic-scale weather phenomena characterized by persistent obstruction of the normal westerly flow and are associated with heat waves, cold spells, flooding, and drought (Glickman, 2012). In Pinheiro et al. (2019) (hereafter PUG19), several 2D algorithms were compared for the detection and characterization of blocking features. It was found that the identification algorithm of Dole and Gordon (1983) (hereafter DG83), which identifies blocks as anomalously high values of geopotential height at $500 \mathrm{hPa}$ (Z500), was a robust method for global block detection and characterization. In this section we will employ TE to generate a climatology of blocking events using the modified DG83 algorithm of PUG19 as applied to MERRA2 reanalysis data (Gelaro et al., 2017).

\subsubsection{Step 1: generate the blocking threshold}

Following PUG19, a grid point is defined as a candidate for being blocked if the Z500 field exceeds a threshold Z500 value. This threshold value must be specified as a function of latitude, longitude, and time, given the geographical and seasonal variations in Z500 climatology. PUG19 suggest a 

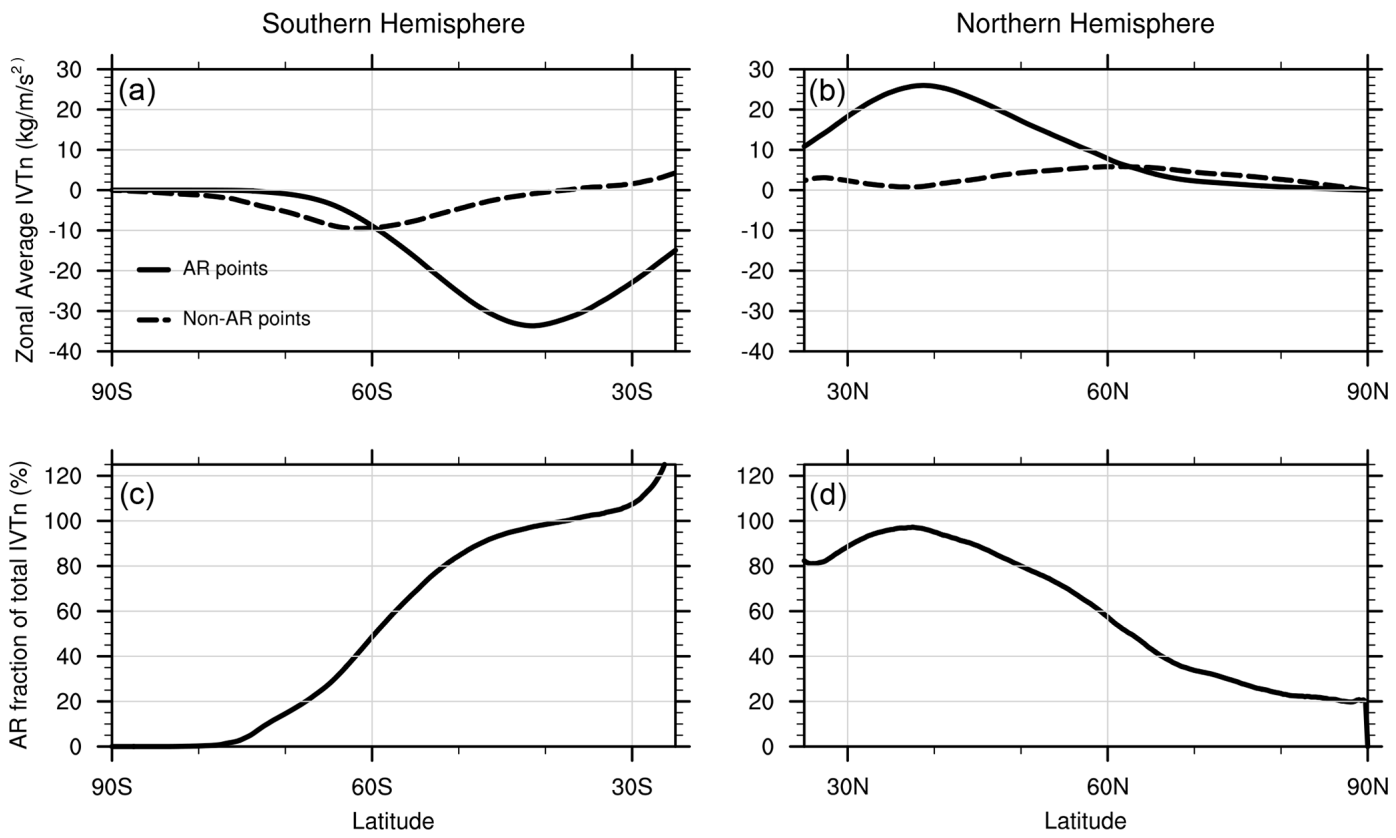

Figure 7. (a, b) Northward IVT (IVTn) from AR and non-AR grid points. (c, d) Fractional contribution to IVTn from AR points by latitude.

threshold value equal to the daily mean Z500 plus the maximum of $100 \mathrm{~m}$ or 1.5 times the daily standard deviation of the Z500 field. Given that only 40 years of MERRA2 reanalysis are available, daily averaged data tends to be quite noisy, and so Fourier smoothing is employed in time and space.

MERRA2 stores the 3D geopotential height variable in the inst3_3d_asm_Np dataset using variable name " $H$ ". For simplicity we assume that the input files contain a list of all files from this dataset from 1 January 1980 to 30 June 2020 (40.5 years). Within this dataset the $500 \mathrm{hPa}$ geopotential height variable can be specified by variable name $\mathrm{H}(500 \mathrm{hPa})$, in which the vertical index is determined automatically by TE. The first step described in Pinheiro et al. (2019) is the construction of a Fourier-filtered longterm daily mean (LTDM) climatology of the Z500 field and its square. The Climatology executable is used in this step and can be executed in parallel:

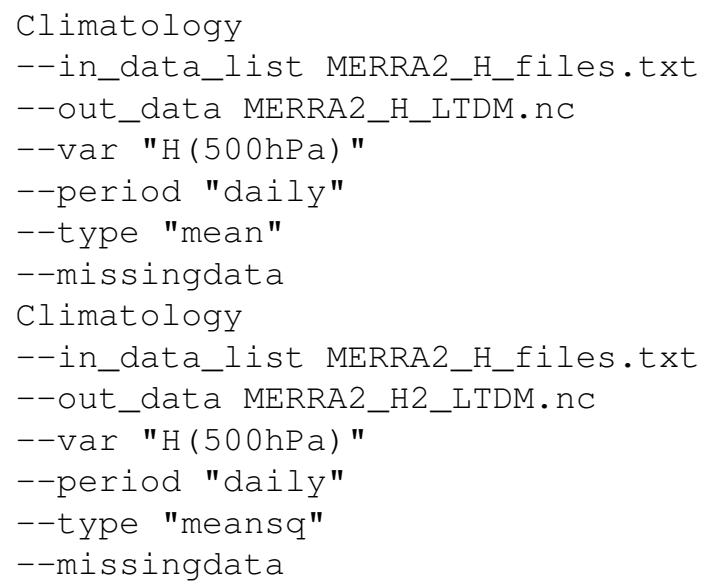

Here the missingdata argument is needed since the $500 \mathrm{hPa}$ pressure surface sometimes falls below the ground in the vicinity of the Himalayas, which is indicated in MERRA2 with missing values. Note that, relevant to subsequent commands, Climatology automatically prepends the descriptor "dailymean_" to the variable, so the final climatology is written to variable "dailymean_H".

We now calculate the standard deviation of the $\mathrm{H}(50 \mathrm{OhPa})$ field using the VariableProcessor:

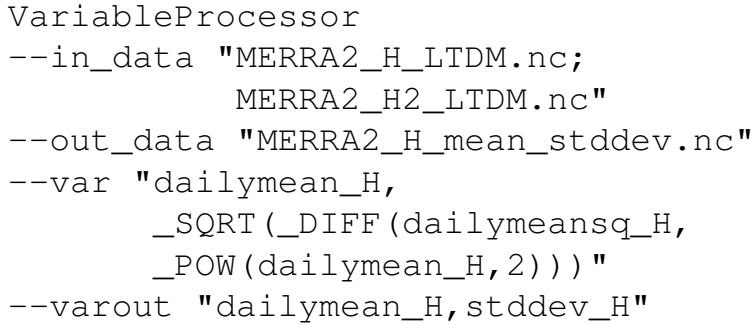

We then apply a 4-mode Fourier filter to both the dailymean_H and stddev_H fields across the time dimension and a 2-mode Fourier filter to the stddev_H field in the zonal direction:

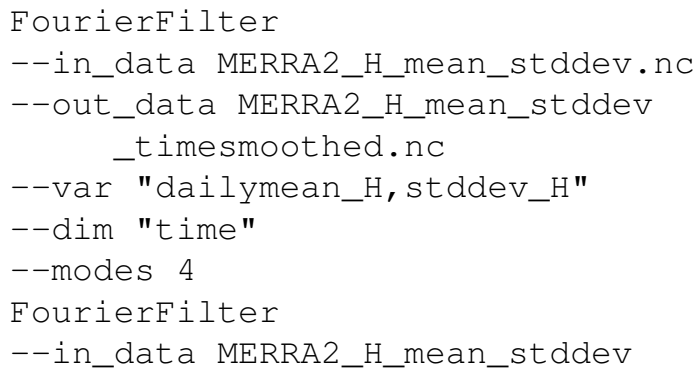



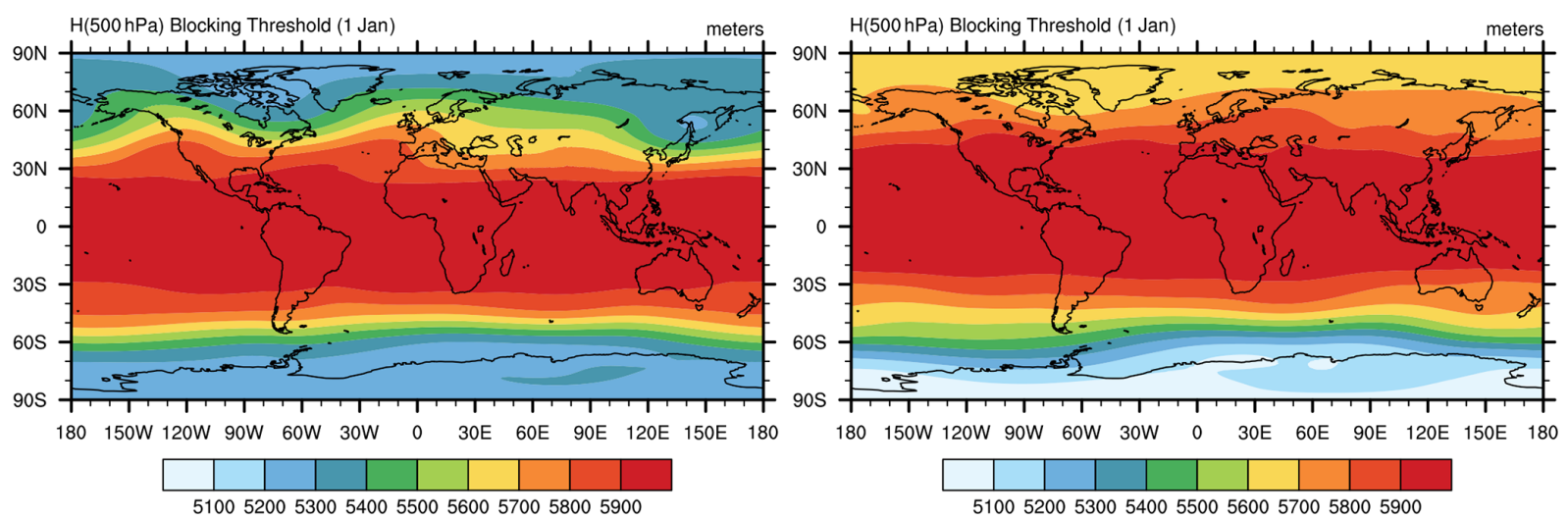

Figure 8. The 1 January and 1 July MERRA2 blocking thresholds generated with the command sequence in Sect. 3.6.1.

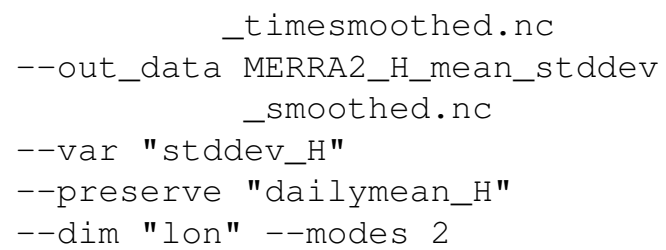

Finally, the threshold is computed as $H 500^{*}=\overline{H 500}+$ $\max \left(1.5 \times H 500_{\text {stddev }}, 100\right)$ via the following command:

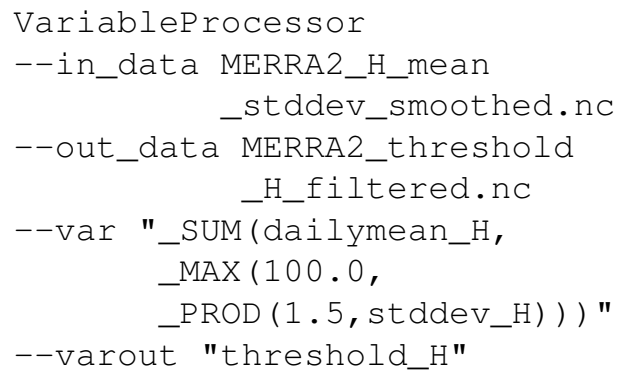

After performing these operations, a $365 \mathrm{~d}$ time series of the threshold field is obtained, which is plotted in Fig. 8 on 1 January and 1 July. Note that this VariableProcessor operation could also have been performed using other climate data processing software, such as NetCDF operators or a simple Python script; however, TE's support for parallelization over files allows these computations to be performed rapidly on supercomputing systems.

\subsubsection{Step 2: identify regions of geopotential above the blocking threshold}

With the LTDM blocking threshold in hand, we now define blocking features as sufficiently large contiguous regions where all points exceed the blocking threshold. As blocking is primarily a midlatitudinal feature, we also focus only on points between $25^{\circ} \mathrm{N} / \mathrm{S}$ and $75^{\circ} \mathrm{N} / \mathrm{S}$.

The newly generated LTDM threshold file is appended to each line of the input data list so it can be accessed by $D e$ tectBlobs. The output file list has the same number of lines as this input list but contains the output files that will contain the binary tags for tagged points.

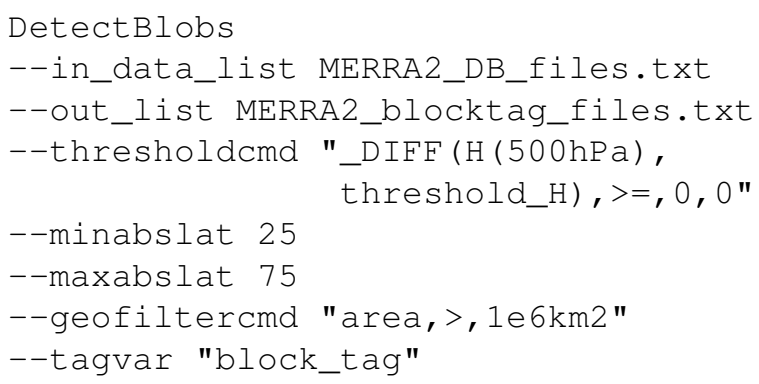

This command tags points as candidates when $500 \mathrm{hPa}$ geopotential height equals or exceeds the blocking threshold. We further remove candidate points equatorward of $25^{\circ} \mathrm{N} / \mathrm{S}$ and poleward of $75^{\circ} \mathrm{N} / \mathrm{S}$ and only retain contiguous regions whose area is at least $10^{6} \mathrm{~km}^{2}$.

\subsubsection{Step 3: enforce a minimum duration for blocks and build climatology}

Besides being regions of anomalously high geopotential, blocking events must also be sufficiently persistent (Glickman, 2012). Although the AMS Glossary of Meteorology uses a typical duration of $7 \mathrm{~d}$ to indicate persistence, we follow PUG19 and retain events which last at least $5 \mathrm{~d}$.

To determine the duration of individual events, we use StitchBlobs to connect blocking features in time, imposing that events are connected in time if they overlap by at least $20 \%$. Features that do not persist for at least $5 \mathrm{~d}$ are discarded. The algorithm used here is described in detail in Sect. 2.6. Here we use the following command:

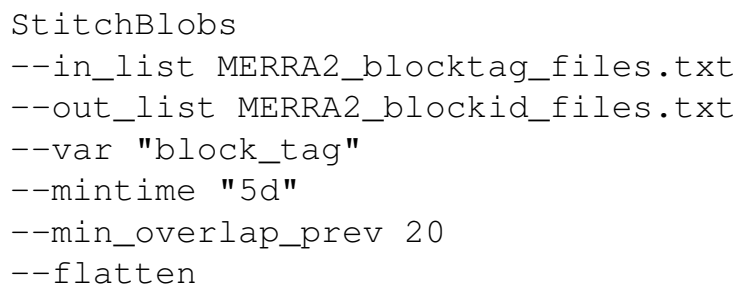



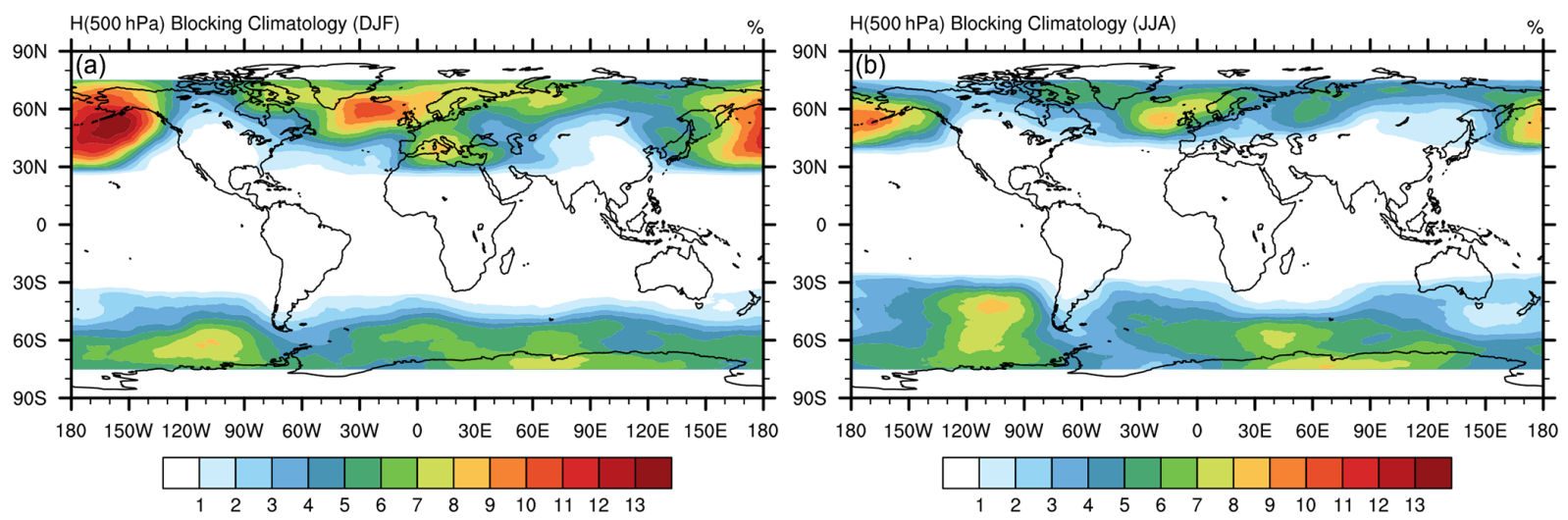

Figure 9. Percentage occurrence of blocking during (a) boreal winter and (b) boreal summer.

The flatten argument indicates that only the binary occurrence of a feature ( 0 or 1$)$ should be recorded after stitching. If this argument was not specified, then each object would be assigned a unique global integer identifier, as described in Sect. 2.6.

To build a seasonal climatology of blocking features, the blocking data from StitchNodes is post-processed. Since the presence of blocking is given with a binary indicator, this command is in effect calculating the fraction of time steps for which blocking occurs:

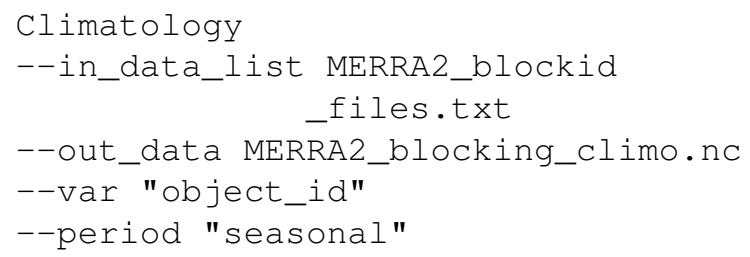

\subsubsection{Blocking climatology results}

The generated blocking climatology in the boreal winter (December-January-February) and boreal summer (JuneJuly-August) is depicted in Fig. 9. Results are generally in agreement with the climatology of Pinheiro et al. (2019) and show substantial wintertime blocking in the North Atlantic and Pacific. A snapshot of blocked regions on 7 December 2013 at 06:00 UTC is further depicted in Fig. 10 (black outlines). The blocking feature present in the northern Pacific at the time was associated with anomalous dry conditions in California and anomalous warmth in Alaska.

\section{Conclusions}

Automated feature tracking capabilities have been frequently and successfully employed throughout the literature to evaluate regional and global models, investigate the drivers and environments of extreme weather events, and understand future change in the statistics of atmospheric features. Feature trackers further provide an important mechanism for extract- ing relevant information from large climate datasets, including reanalysis and observational datasets, and climate model simulations. This is particularly important as the stakeholder needs for climate data associated with societally relevant impacts grow larger.

As there are significant overlaps in the core functionality of these trackers, there is a clear added benefit to integrating these kernels within a single framework. TempestExtremes (TE) is one such framework, with generalized kernels for identifying, characterizing, and analyzing both nodal (point) and areal features. While version 1 of TE was primarily focused on tropical and extratropical cyclones (Ullrich and Zarzycki, 2017), version 2 of TE has since added substantial new functionality for areal feature tracking, characterizing and compositing features, and more dataset-agnostic parameters and thresholds. TE focuses on high-throughput data processing, including MPI support for core executables to parallelize file system operations. Such a framework has clear scientific relevance, enabling the development of feature catalogues and addressing questions related to specific features, including those commonly associated with extreme weather. As TE further exposes all tuning parameters, users are able to easily investigate sensitivities of the tracker or optimize the tracker for detecting particular features.

In this paper we have described some of the newer algorithmic kernels exposed by TE and shown how these kernels can be composited to build robust tracking algorithms for many important atmospheric features. The tracking capability enables the probing of deeper scientific questions related to individual features. To demonstrate this functionality, TE was employed in Sect. 3.3 for the tracking of tropical cyclones (TCs) and calculating the fractional contribution of TC precipitation to total precipitation in each region. Ultimately, with the suite of trackers provided by TE, a global climatology can be constructed that attributes total precipitation to features; e.g., using TE we showed that TCs contribute to $20 \%-40 \%$ of total precipitation in the tropical regions of the Pacific and South Indian Ocean in both satellite observations and ERA5 reanalysis. In Sect. 3.4, an analysis 


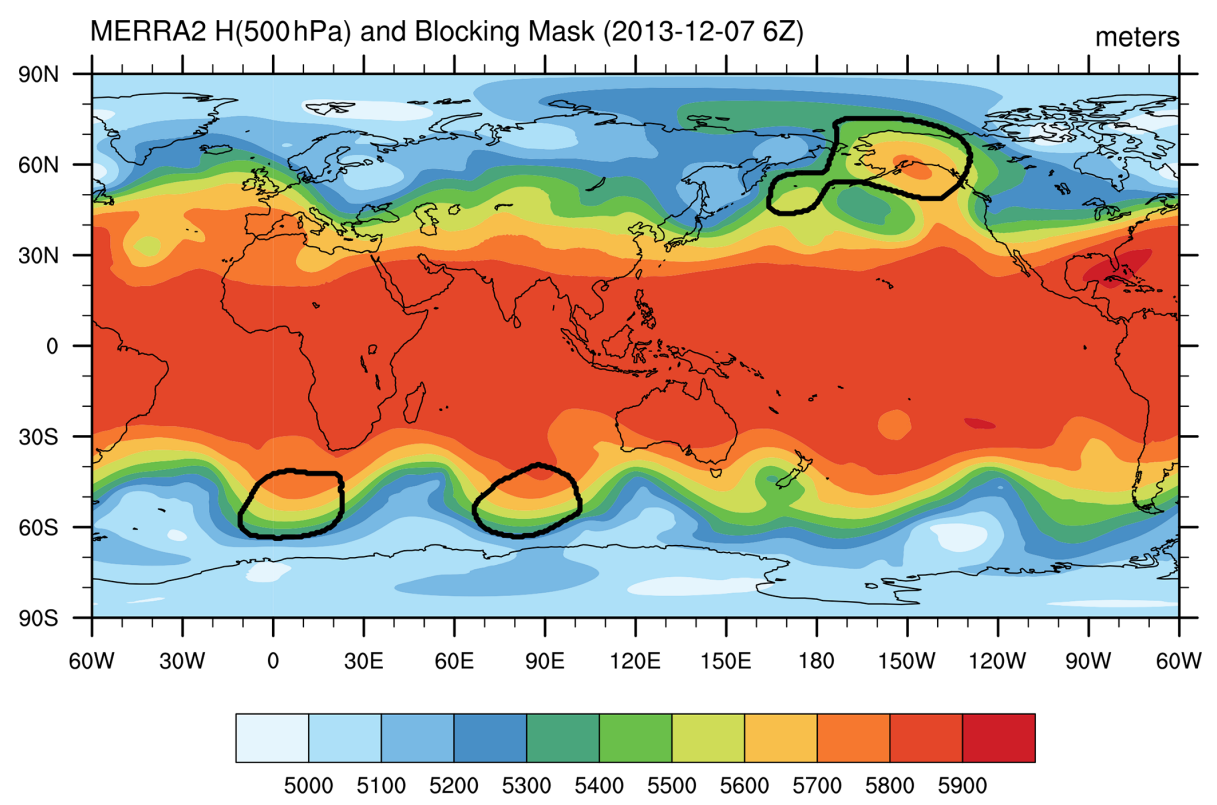

Figure 10. A snapshot of blocked regions in MERRA2 data detected on 7 December 2013 06:00 UTC (the three black outlines) atop the $\mathrm{H}(500 \mathrm{hPa})$ field at this time.

of the composited characters of extratropical cyclones in the CESM large ensemble was performed to understand climatological track density and meteorological fields, enabling the evaluation of model performance and better communication of the relevant underlying processes. In Sect. 3.5, a novel atmospheric river detection algorithm was developed using $\mathrm{TE}$ and validated against meridional moisture transport put forward in Zhu and Newell (1998). Finally, in Sect. 3.6, TE was used to construct a seasonal climatology of atmospheric blocking. Notably, the data reductions demonstrated in these sections could support model evaluation via feature-specific and process-oriented metrics and diagnostics.

Nonetheless, TE v2.1 does have several limitations that may be addressed in future versions. At present, TE does not support detection of subgrid-scale extrema (e.g., using harmonics as in Benestad and Chen, 2006, or bicubics as in Murray and Simmonds, 1991), although this feature is largely necessitated by coarse-spatial-resolution inputs. TE also does not allow for extrapolation of the search position, as in some TC and ETC tracking schemes (Marchok, 2002). TE does not provide support for inline or offline percentile calculations, zonal $/$ meridional averages, or time derivatives. Nor does version 2.1 include support for common calculus operators (e.g., relative vorticity, divergence, vector dot gradient, gradient magnitude), although experimental versions of these operators have been added in version 2.2. It is also missing operations sometimes used for areal feature tracking, including dilation of areal features (Heikenfeld et al., 2019; Feng et al., 2018) and geometric operations sometimes used in AR tracking, including filtering of ARs with a low width / length ratio (Mundhenk et al., 2016); support for these features is anticipated before version 3.0. Additionally, as mentioned earlier in this paper, parallelism is presently only supported across files; given that data products sometimes concatenate many times within a single file, support for parallelism within files is also desirable. In general, development of TE has been guided by the needs of its user base, with many current features having been added by request; we anticipate this to continue into the future.

It is expected that TE will continue to evolve to meet the needs of the scientific community. New kernels are already being investigated that encompass the functionality present in other stand-alone trackers. A continued focus will be on maximizing TE's robustness across datasets so as to ensure the framework is useful for stand-alone users and operational modeling centers or for comparative analysis across reanalysis products, multi-model ensembles (Eyring et al., 2016), and single model ensembles (Kay et al., 2015). Finally, new capabilities to perform the direct evaluation of simulation products in TE are now being developed, using the characteristics of tracked features as evaluation metrics. 


\section{Appendix A: Stereographic projection}

The stereographic projection is used in the construction of composites using NodeFileFilter. The equations used for projection are provided here for reference.

The forward stereographic projection around a central point $\left(\lambda_{0}, \phi_{0}\right)$ is given by the following:

$K=\left[1+\sin \phi \sin \phi_{0}+\cos \phi \cos \phi_{0} \cos \left(\lambda-\lambda_{0}\right)\right]^{-1}$,

$X\left(\lambda, \phi ; \lambda_{0}, \phi_{0}\right)=K \cos \phi \sin \left(\lambda-\lambda_{0}\right)$,

$Y\left(\lambda, \phi ; \lambda_{0}, \phi_{0}\right)=$

$K\left[\cos \phi_{0} \sin \phi-\sin \phi_{0} \cos \phi \cos \left(\lambda-\lambda_{0}\right)\right]$.

The inverse projection is given by the following:

$\rho=\sqrt{X^{2}+Y^{2}}$,

$c=2 \arctan (\rho / 2)$,

$\phi\left(X, Y ; \lambda_{0}, \phi_{0}\right)=$

$\begin{cases}\phi_{0}, & \text { if } \rho=0, \\ \arcsin \left[\cos c \sin \phi_{0}+(Y / \rho) \sin c \cos \phi_{0}\right], & \text { otherwise. }\end{cases}$

$\lambda\left(X, Y ; \lambda_{0}, \phi_{0}\right)=$

$\begin{cases}\lambda_{0}, & \text { if } \rho=0, \\ \lambda_{0}+\arctan 2[X \sin c, & \text { otherwise. } \\ \left.\rho \cos \phi_{0} \cos c,-Y \sin \phi_{0} \sin c\right] & \end{cases}$

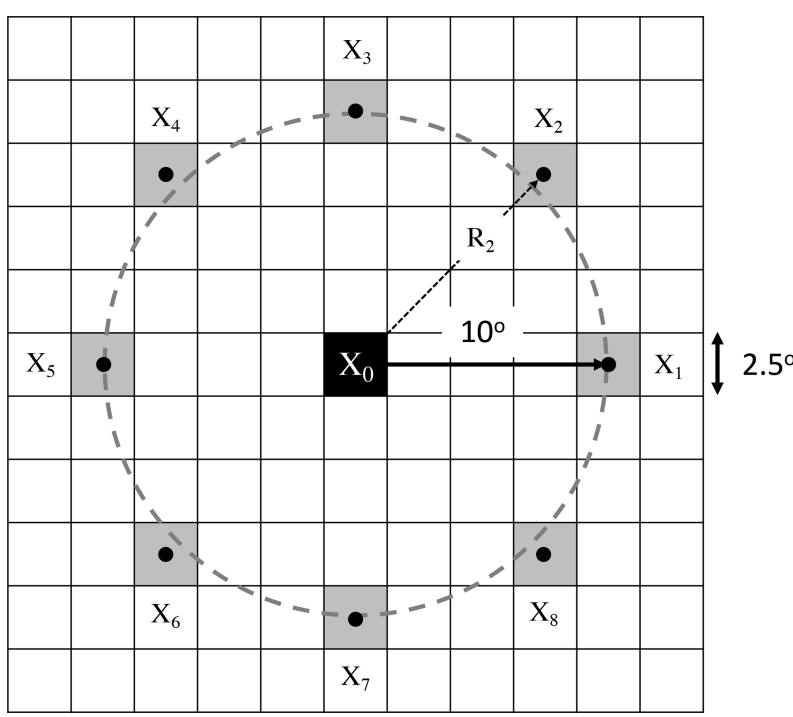

Figure B1. For a uniform (stereographic) grid with grid spacing of $2.5^{\circ} \mathrm{GCD}$, an illustration of the grid points used in the calculation of the Laplacian with eight radial points and radius of $10^{\circ} \mathrm{GCD}$. This operator is constructed in TE using notation _LAPLACIAN $\{8,10\}$. The central grid point is shaded black, and the modified centroids are shaded in gray.

\section{Appendix B: Laplacian operator}

The stereographic discrete pointwise Laplacian operator defined in TE is constructed in a grid-independent manner using a discrete radial formulation. To begin, a set of $N$ initial sample points are generated using a ring of radius $R$ degrees around each grid point $\mathbf{X}_{0}$. Using a k-d-tree-based implementation, the nearest grid points to each initial sample point are then selected to give a set of adjusted grid points $\mathbf{X}_{n}$ with $n=1, \ldots, N$. For each of the initial sample points we then define the distance $D_{n}$ by the great circle distance between grid point $X_{0}$ and $X_{n}$. The averaged Laplacian over a disk of radius $R / 2$ is then computed discretely using the divergence theorem on the stereographic plane and a centered difference approximation for the radial derivative:

$$
\begin{aligned}
\frac{1}{\pi(R / 2)^{2}} \int \nabla^{2} q \mathrm{~d} A & =\frac{4}{\pi R^{2}} \oint \nabla q \cdot \mathrm{d} S \\
& \approx \frac{4}{\pi R^{2}} \sum_{n=0}^{N-1}\left(\frac{q_{n}-q_{0}}{D_{n}}\right)\left(\frac{\pi R}{N}\right) \\
& =\frac{4}{N R} \sum_{n=0}^{N-1} \frac{q_{n}-q_{0}}{D_{n}},
\end{aligned}
$$

where $q_{n}$ denotes the value of the field at $X_{n}$. 
Code availability. The TempestExtremes v2.1 release is available from ZENODO at https://doi.org/10.5281/zenodo.4385656 (Ullrich et al., 2021). The GitHub repository used for ongoing code development is available at https:/github.com/ClimateGlobalChange/ tempestextremes (last access: 15 July 2021) (Ullrich, 2021).

Author contributions. PAU wrote the software package with input from all involved authors and others in the community. CMZ and KAR advised on the algorithms for tracking tropical cyclones and extratropical cyclones. CMZ further authored the extratropical cyclone section of the paper. EEM advised on and tuned the algorithm for detecting and characterizing atmospheric rivers. MCP developed the algorithm for detecting and characterizing atmospheric blocks. AMS wrote the section on contributions of precipitation from tropical cyclones.

Competing interests. The authors declare that they have no competing interests.

Disclaimer. Publisher's note: Copernicus Publications remains neutral with regard to jurisdictional claims in published maps and institutional affiliations.

Acknowledgements. The authors would like to acknowledge the feedback and bug reports from our many users, particularly Alan Rhoades, Karthik Belaguru, Vishnu Sasidharan Nair, Erica Bower, and Yumin Moon. This research used resources of the National Energy Research Scientific Computing Center, a DOE Office of Science User Facility supported by the Office of Science of the US Department of Energy under contract no. DE-AC02-05CH11231.

Financial support. This work has been supported by Department of Energy Office of Science award number DE-SC0016605, “A Framework for Improving Analysis and Modeling of Earth System and Intersectoral Dynamics at Regional Scales" (HyperFACETS), NASA award NNX16AG62G "TempestExtremes: Indicators of change in the characteristics of extreme weather," NASA award 80NSSC19K0717 "Quantifying the link between organized convection and extreme precipitation," and NOAA MAPP award NA19OAR4310288 "Future changes in the frequency of winter snowstorms and their impact on snowfall and snow water equivalent." This project is also supported by the National Institute of Food and Agriculture, US Department of Agriculture, hatch project under California Agricultural Experiment Station project accession no. 1016611 .

Review statement. This paper was edited by Fabien Maussion and reviewed by Hristo Chipilski and one anonymous referee.

\section{References}

Atkinson, G. D. and Holliday, C. R.: Tropical cyclone minimum sea level pressure/maximum sustained wind relationship for the Western North Pacific, Mon. Weather Rev., 105, 421-427, https://doi.org/10.1175/15200493(1977)105<0421:TCMSLP>2.0.CO;2, 1977.

Balaguru, K., Leung, L. R., Van Roekel, L. P., Golaz, J.-C., Ullrich, P. A., Caldwell, P. M., Hagos, S. M., Harrop, B. E., and Mametjanov, A.: Characterizing Tropical Cyclones in the Energy Exascale Earth System Model Version 1, J. Adv. Model. Earth Sy., 12, e2019MS002024, https://doi.org/10.1029/2019MS002024, 2020.

Bell, G. D., Halpert, M. S., Schnell, R. C., Higgins, R. W., Lawrimore, J., Kousky, V. E., Tinker, R., Thiaw, W., Chelliah, M., and Artusa, A.: Climate Assessment for 1999, B. Am. Meteorol. Soc., 81, S1-S50, https://doi.org/10.1175/15200477(2000)81[s1:CAF]2.0.CO;2, 2000.

Benestad, R. and Chen, D.: The use of a calculus-based cyclone identification method for generating storm statistics, Tellus A, 58, 473-486, 2006.

Browning, K. A.: Conceptual Models of Precipitation Systems, Weather Forecast., 1, 23-41, https://doi.org/10.1175/15200434(1986)001<0023:CMOPS>2.0.CO;2, 1986.

Camargo, S. J., Giulivi, C. F., Sobel, A. H., Wing, A. A., Kim, D., Moon, Y., Strong, J. D., Del Genio, A. D., Kelley, M., Murakami, H., Reed, K., Scoccimarro, E., Vecchi, G., Wehner, M., Zarzycki, C., and Zhao, M.: Characteristics of model tropical cyclone climatology and the large-scale environment, J. Climate, 33, 44634487, 2020.

Catalano, A. J., Broccoli, A. J., Kapnick, S. B., and Janoski, T. P.: High-Impact Extratropical Cyclones along the Northeast Coast of the United States in a Long Coupled Climate Model Simulation, J. Climate, 32, 2131-2143, https://doi.org/10.1175/JCLI-D18-0376.1, 2019.

Chavas, D. R. and Reed, K. A.: Dynamical aquaplanet experiments with uniform thermal forcing: System dynamics and implications for tropical cyclone genesis and size, J. Atmos. Sci., 76, 22572274, 2019.

Chavas, D. R., Reed, K. A., and Knaff, J. A.: Physical understanding of the tropical cyclone wind-pressure relationship, Nat. Commun., 8, 1-11, https://doi.org/10.1038/s41467-017-015469, 2017.

Chipilski, H. G., Wang, X., and Parsons, D. B.: Object-based algorithm for the identification and tracking of convective outflow boundaries in numerical models, Mon. Weather Rev., 146, 41794200, 2018.

Clark, A. J., Bullock, R. G., Jensen, T. L., Xue, M., and Kong, F.: Application of object-based time-domain diagnostics for tracking precipitation systems in convection-allowing models, Weather Forecast., 29, 517-542, 2014.

Colle, B. A., Booth, J. F., and Chang, E. K. M.: A Review of Historical and Future Changes of Extratropical Cyclones and Associated Impacts Along the US East Coast, Curr. Clim. Change Rep., 1, 125-143, https://doi.org/10.1007/s40641-015-0013-7, 2015.

Dacre, H.: A review of extratropical cyclones: Observations and conceptual models over the past 100 years, Weather, 75, 4-7, https://doi.org/10.1002/wea.3653, 2020. 
Davini, P. and D'Andrea, F.: Northern Hemisphere atmospheric blocking representation in global climate models: Twenty years of improvements?, J. Climate, 29, 8823-8840, 2016.

Dean, J. and Ghemawat, S.: MapReduce: simplified data processing on large clusters, Commun. ACM, 51, 107-113, 2008.

Delanoy, R. L. and Troxel, S. W.: Machine Intelligent Gust Front Detection, Lincoln Lab. J., 6, 187-212, 1993.

Di Luca, A., Evans, J. P., Pepler, A., Alexander, L., and Argüeso, D.: Resolution sensitivity of cyclone climatology over eastern Australia using six reanalysis products, J. Climate, 28, 9530-9549, 2015.

Dole, R. M. and Gordon, N. D.: Persistent anomalies of the extratropical Northern Hemisphere wintertime circulation: Geographical distribution and regional persistence characteristics, Mon. Weather Rev., 111, 1567-1586, 1983.

Emanuel, K.: Increasing destructiveness of tropical cyclones over the past 30 years, Nature, 436, 686-688, 2005.

European Centre for Medium-Range Weather Forecasts: ERA5 Reanalysis (0.25 Degree Latitude-Longitude Grid), in: Research Data Archive at the National Center for Atmospheric Research, Computational and Information Systems Laboratory, National Center for Atmospheric Research (NCAR), https://doi.org/10.5065/BH6N-5N20, 2019.

Eyring, V., Bony, S., Meehl, G. A., Senior, C. A., Stevens, B., Stouffer, R. J., and Taylor, K. E.: Overview of the Coupled Model Intercomparison Project Phase 6 (CMIP6) experimental design and organization, Geosci. Model Dev., 9, 1937-1958, https://doi.org/10.5194/gmd-9-1937-2016, 2016.

Feng, Z., Leung, L. R., Houze Jr, R. A., Hagos, S., Hardin, J., Yang, Q., Han, B., and Fan, J.: Structure and evolution of mesoscale convective systems: Sensitivity to cloud microphysics in convection-permitting simulations over the United States, J. Adv. Model. Earth Sy., 10, 1470-1494, 2018.

Field, P. R. and Wood, R.: Precipitation and cloud structure in midlatitude cyclones, J. Climate, 20, 233-254, https://doi.org/10.1175/JCLI3998.1, 2007.

Gelaro, R., McCarty, W., Suárez, M. J., Todling, R., Molod, A., Takacs, L., Randles, C. A., Darmenov, A., Bosilovich, M. G., Reichle, R., Wargan, K., Coy, L., Cullather, R., Draper, C., Akella, S., Buchard, V., Conaty, A., da Silva, A. M., Gu, W., Kim, G.K., Koster, R., Lucchesi, R., Merkova, D., Nielsen, J. E., Partyka, G., Pawson, S., Putman, W., Rienecker, M., Schubert, S. D., Sienkiewicz, M., and Zhao, B.: The Modern-Era Retrospective Analysis for Research and Applications, version 2 (MERRA-2), J. Climate, 30, 5419-5454, 2017.

Glickman, T. S.: Blocking, in: Glossary of Meteorology, Am. Meteorol. Soc., Boston, Mass., available at: https://glossary.ametsoc. org/wiki/Blocking (last access: 15 July 2021), 2012.

Grotjahn, R., Black, R., Leung, R., Wehner, M. F., Barlow, M., Bosilovich, M., Gershunov, A., Gutowski, W. J., Gyakum, J. R., Katz, R. W., Lee, Y.-Y., Lim, Y.-K., and Prabhat: North American extreme temperature events and related large scale meteorological patterns: A review of statistical methods, dynamics, modeling, and trends, Clim. Dynam., 46, 1151-1184, 2016.

Haarsma, R. J., Roberts, M. J., Vidale, P. L., Senior, C. A., Bellucci, A., Bao, Q., Chang, P., Corti, S., Fučkar, N. S., Guemas, V., von Hardenberg, J., Hazeleger, W., Kodama, C., Koenigk, T., Leung, L. R., Lu, J., Luo, J.-J., Mao, J., Mizielinski, M. S., Mizuta, R., Nobre, P., Satoh, M., Scoccimarro, E., Semmler, T., Small, J., and von Storch, J.-S.: High Resolution Model Intercomparison Project (HighResMIP v1.0) for CMIP6, Geosci. Model Dev., 9, 4185-4208, https://doi.org/10.5194/gmd-9-4185-2016, 2016.

Hart, R. E.: A cyclone phase space derived from thermal wind and thermal asymmetry, Mon. Weather Rev., 131, 585-616, 2003.

Hassani, H., Huang, X., and Silva, E.: Big Data and climate change, Big Data and Cognitive Computing, 3, 12, https://doi.org/10.3390/bdcc3010012, 2019.

Heikenfeld, M., Marinescu, P. J., Christensen, M., Watson-Parris, D., Senf, F., van den Heever, S. C., and Stier, P.: tobac 1.2: towards a flexible framework for tracking and analysis of clouds in diverse datasets, Geosci. Model Dev., 12, 4551-4570, https://doi.org/10.5194/gmd-12-4551-2019, 2019.

Hersbach, H., Bell, B., Berrisford, P., Hirahara, S., Horányi, A., Muñoz-Sabater, J., Nicolas, J., Peubey, C., Radu, R., Schepers, D., Simmons, A., Soci, C., Abdalla, S., Abellan, X., Balsamo, G., Bechtold, P., Biavati, G., Bidlot, J., Bonavita, M., Chiara, G. D., Dahlgren, P., Dee, D., Diamantakis, M., Dragani, R., Flemming, J., Forbes, R., Fuentes, M., Geer, A., Haimberger, L., Healy, S., Hogan, R. J., Hólm, E., Janisková, M., Keeley, S., Laloyaux, P., Lopez, P., Lupu, C., Radnoti, G., de Rosnay, P., Rozum, I., Vamborg, F., Villaume, S., and Thépaut, J.: The ERA5 global reanalysis, Q. J. Roy. Meteor. Soc., 146, 1999-2049, 2020.

Hodges, K., Cobb, A., and Vidale, P. L.: How well are tropical cyclones represented in reanalysis datasets?, J. Climate, 30, 52435264, https://doi.org/10.1175/JCLI-D-16-0557.1, 2017.

Holland, G.: A revised hurricane pressure-wind model, Mon. Weather Rev., 136, 3432-3445, https://doi.org/10.1175/2008MWR2395.1, 2008.

Hope, P., Keay, K., Pook, M., Catto, J., Simmonds, I., Mills, G., McIntosh, P., Risbey, J., and Berry, G.: A comparison of automated methods of front recognition for climate studies: A case study in southwest Western Australia, Mon. Weather Rev., 142, 343-363, 2014.

Huang, H., Patricola, C. M., Bercos-Hickey, E., Zhou, Y., Rhoades, A., Risser, M. D., and Collins, W. D.: Sources of SubseasonalTo-Seasonal Predictability of Atmospheric Rivers and Precipitation in the Western United States, J. Geophys. Res.-Atmos., 126, e2020JD034053, https://doi.org/10.1029/2020JD034053, 2021.

Huffman, G. J., Bolvin, D. T., Nelkin, E. J., Wolff, D. B., Adler, R. F., Gu, G., Hong, Y., Bowman, K. P., and Stocker, E. F.: The TRMM Multisatellite Precipitation Analysis (TMPA): Quasi-global, multiyear, combined-sensor precipitation estimates at fine scales, J. Hydrometeor., 8, 38-55, https://doi.org/10.1175/JHM560.1, 2007.

Hurley, J. V. and Boos, W. R.: A global climatology of monsoon low-pressure systems, Q. J. Roy. Meteor. Soc., 141, 1049-1064, 2015.

Kay, J. E., Deser, C., Phillips, A., Mai, A., Hannay, C., Strand, G., Arblaster, J. M., Bates, S., Danabasoglu, G., Edwards, J., Holland, M., Kushner, P., Lamarque, J.-F., Lawrence, D., Lindsay, K., Middleton, A., Munoz, E., Neale, R., Oleson, K., Polvani, L., and Vertenstein, M.: The Community Earth System Model (CESM) large ensemble project: A community resource for studying climate change in the presence of internal climate variability, B. Am. Meteorol. Soc., 96, 1333-1349, 2015.

Khouakhi, A., Villarini, G., and Vecchi, G. A.: Contribution of tropical cyclones to rainfall at the global scale, J. Climate, 30, 359372, https://doi.org/10.1175/JCLI-D-16-0298.1, 2017. 
Kiehl, J. T., Zarzycki, C. M., Shields, C. A., and Rothstein, M. V.: Simulated changes to tropical cyclones across the Paleocene-Eocene Thermal Maximum (PETM) boundary, Palaeogeogr. Palaeoclimatol., 572, 110421, https://doi.org/10.1016/j.palaeo.2021.110421, 2021.

Knaff, J. A. and Zehr, R. M.: Reexamination of tropical cyclone wind-pressure relationships, Weather Forecast., 22, 71-88, https://doi.org/10.1175/WAF965.1, 2007.

Knapp, K. R., Kruk, M. C., Levinson, D. H., Diamond, H. J., and Neumann, C. J.: The International Best Track Archive for Climate Stewardship (IBTrACS) unifying tropical cyclone data, B. Am. Meteorol. Soc., 91, 363-376, 2010.

Li, F., Chavas, D. R., Reed, K. A., and Dawson II, D. T.: Climatology of severe local storm environments and synoptic-scale features over North America in ERA5 reanalysis and CAM6 simulation, J. Climate, 33, 8339-8365, https://doi.org/10.1175/JCLID-19-0986.1, 2020.

Marchok, T. P.: How the NCEP tropical cyclone tracker works, in: Preprints, 25th Conf. on Hurricanes and Tropical Meteorology, San Diego, CA, Am. Meteor. Soc., vol. 1, 2002.

McClenny, E. E., Ullrich, P. A., and Grotjahn, R.: Sensitivity of atmospheric river vapor transport and precipitation to uniform sea-surface temperature increases, J. Geophys. Res.-Atmos., 125, e2020JD033421, https://doi.org/10.1029/2020JD033421, 2020.

Michaelis, A. C. and Lackmann, G. M.: Climatological changes in the extratropical transition of tropical cyclones in high-resolution global simulations, J. Climate, 32, 8733-8753, 2019.

Michaelis, A. C. and Lackmann, G. M.: Storm-scale dynamical changes of extratropical transition events in present-day and future high-resolution global simulations, J. Climate, 34, 50375062, 2021.

Moon, Y., Kim, D., Camargo, S. J., Wing, A. A., Sobel, A. H., Murakami, H., Reed, K. A., Scoccimarro, E., Vecchi, G. A., Wehner, M. F., Zarzycki, C. M., and Zhao, M.: Azimuthally averaged wind and thermodynamic structures of tropical cyclones in global climate models and their sensitivity to horizontal resolution, J. Climate, 33, 1575-1595, 2020.

Mundhenk, B. D., Barnes, E. A., and Maloney, E. D.: All-season climatology and variability of atmospheric river frequencies over the North Pacific, J. Climate, 29, 4885-4903, 2016.

Murakami, H.: Tropical cyclones in reanalysis data sets, Geophys. Res. Lett., 41, 2133-2141, https://doi.org/10.1002/2014GL059519, 2014.

Murata, A., Sasaki, H., Kawase, H., and Nosaka, M.: The development of a resolution-independent tropical cyclone detection scheme for high-resolution climate model simulations, J. Meteorol. Soci. Jpn. Ser. II, 97, 519-531, 2019.

Murray, R. J. and Simmonds, I.: A numerical scheme for tracking cyclone centres from digital data, Aust. Meteorol. Mag., 39, 155166, 1991.

Neu, U., Akperov, M. G., Bellenbaum, N., Benestad, R., Blender, R., Caballero, R., Cocozza, A., Dacre, H. F., Feng, Y., Fraedrich, K., Grieger, J., Gulev, S., Hanley, J., Hewson, T., Inatsu, M., Keay, K., Kew, S. F., Kindem, I., Leckebusch, G. C., Liberato, M. L. R., Lionello, P., Mokhov, I., Pinto, J. G., Raible, C. C., Reale, M., Rudeva, I., Schuster, M., Simmonds, I., Sinclair, M.,, Sprenger, M., Tilinina, N. D., Trigo, I. F., Ulbrich, S., Ulbrich, U., Wang, X. L., and Wernli, H.: IMILAST: A community ef- fort to intercompare extratropical cyclone detection and tracking algorithms, B. Am. Meteorol. Soc., 94, 529-547, 2013.

Parfitt, R., Czaja, A., and Seo, H.: A simple diagnostic for the detection of atmospheric fronts, Geophys. Res. Lett., 44, 4351-4358, 2017.

Patricola, C. M., O’Brien, J. P., Risser, M. D., Rhoades, A. M., O'Brien, T. A., Ullrich, P. A., Stone, D. A., and Collins, W. D.: Maximizing ENSO as a source of western US hydroclimate predictability, Clim. Dynam., 54, 351-372, 2020.

Payne, A. E., Demory, M.-E., Leung, L. R., Ramos, A. M., Shields, C. A., Rutz, J. J., Siler, N., Villarini, G., Hall, A., and Ralph, F. M.: Responses and impacts of atmospheric rivers to climate change, Nat. Rev. Earth Environ., 1, 143-157, 2020.

Pendergrass, A. G., Reed, K. A., and Medeiros, B.: The link between extreme precipitation and convective organization in a warming climate: Global radiative-convective equilibrium simulations, Geophys. Res. Lett., 43, 11445-11452, https://doi.org/10.1002/2016GL071285, 2016.

Pinheiro, M., Ullrich, P., and Grotjahn, R.: Atmospheric blocking and intercomparison of objective detection methods: flow field characteristics, Clim. Dynam., 53, 4189-4216, 2019.

Powell, M. D. and Reinhold, T. A.: Tropical cyclone destructive potential by integrated kinetic energy, B. Am. Meteorol. Soc., 88, 513-526, 2007.

Prat, O. P. and Nelson, B. R.: Mapping the world's tropical cyclone rainfall contribution over land using the TRMM Multisatellite Precipitation Analysis, Water Resour. Res., 49, 72367254, https://doi.org/10.1002/wrcr.20527, 2013.

Prein, A. F., Liu, C., Ikeda, K., Trier, S. B., Rasmussen, R. M., Holland, G. J., and Clark, M. P.: Increased rainfall volume from future convective storms in the US, Nat. Clim. Change, 7, 880-884, 2017.

Reed, K., Wehner, M. F., Stansfield, A. M., and Zarzycki, C. M.: Anthropogenic influence on hurricane Dorian's extreme rainfall, B. Am. Meteorol. Soc., 102, S9-S15, 2021.

Reed, K. A., Stansfield, A., Wehner, M., and Zarzycki, C.: Forecasted attribution of the human influence on Hurricane Florence, Sci. Adv., 6, eaaw9253, https://doi.org/10.1126/sciadv.aaw9253, 2020.

Rhoades, A., Jones, A., Srivastava, A., Huang, H., O’Brien, T., Patricola, C., Ullrich, P., Wehner, M., and Zhou, Y.: The shifting scales of Western US landfalling atmospheric rivers under climate change, Geophys. Res. Lett., 47, e2020GL089096, https://doi.org/10.1029/2020GL089096, 2020a.

Rhoades, A. M., Jones, A. D., O’Brien, T. A., O’Brien, J. P., Ullrich, P. A., and Zarzycki, C. M.: Influences of North Pacific Ocean domain extent on the Western US winter hydroclimatology in variable-resolution CESM, J. Geophys. Res.-Atmos., 125, e2019JD031977, https://doi.org/10.1029/2019JD031977, 2020b.

Roberts, M. J., Camp, J., Seddon, J., Vidale, P. L., Hodges, K., Vannière, B., Mecking, J., Haarsma, R., Bellucci, A., Scoccimarro, E., Caron, L.-P., Chauvin, F., Terray, L., Valcke, S., Moine, M.-P., Putrasahan, D., Roberts, C., Senan, R., Zarzycki, C., Ullrich, P., Yamada, Y., Mizuta, R., Kodama, C., Fu, D., Zhang, Q., Danabasoglu, G., Rosenbloom, N., Wang, H., and Wu, L.: Projected future changes in tropical cyclones using the CMIP6 HighResMIP multimodel ensemble, Geophys. Res. Lett., 47, e2020GL088662, https://doi.org/10.1029/2020GL088662, 2020a. 
Roberts, M. J., Camp, J., Seddon, J., Vidale, P. L., Hodges, K., Vanniere, B., Mecking, J., Haarsma, R., Bellucci, A., Scoccimarro, E., Caron, L.-P., Chauvin, F., Terray, L., Valcke, S., Moine, M.P., Putrasahan, D., Roberts, C., Senan, R., Zarzycki, C., Ullrich, P., Yamada, Y., Mizuta, R., Kodama, C., Fu, D., Zhang, Q., Danabasoglu, G., Rosenbloom, N., Wang, H., and Wu, L.: Impact of model resolution on tropical cyclone simulation using the HighResMIP-PRIMAVERA multimodel ensemble, J. Climate, 33, 2557-2583, 2020b.

Rutz, J. J., Shields, C. A., Lora, J. M., Payne, A. E., Guan, B., Ullrich, P., O’Brien, T., Leung, L. R., Ralph, F. M., Wehner, M., Brands, S., Collow, A., Goldenson, N., Gorodetskaya, I., Griffith, H., Kashinath, K., Kawzenuk, B., Krishnan, H., Kurlin, V., Lavers, D., Magnusdottir, G., Mahoney, K., McClenny, E., Muszynski, G., Nguyen, P. D., Prabhat, Qian, Y., Ramos, A. M., Sarangi, C., Sellars, S., Shulgina, T., Tome, R., Waliser, D., Walton, D., Wick, G., Wilson, A. M., and Viale, M.: The Atmospheric River Tracking Method Intercomparison Project (ARTMIP): Quantifying uncertainties in atmospheric river climatology, J. Geophys. Res.-Atmos., 124, 13777-13802, 2019.

Schemm, S., Rudeva, I., and Simmonds, I.: Extratropical fronts in the lower troposphere-global perspectives obtained from two automated methods, Q. J. Roy. Meteor. Soc., 141, 1686-1698, 2015.

Schenkel, B. A. and Hart, R. E.: An examination of tropical cyclone position, intensity, and intensity life cycle within atmospheric reanalysis datasets, J. Climate, 25, 3453-3475, https://doi.org/10.1175/2011JCLI4208.1, 2012.

Schenkel, B. A., Lin, N., Chavas, D., Oppenheimer, M., and Brammer, A.: Evaluating outer tropical cyclone size in reanalysis datasets using QuikSCAT data, J. Climate, 30, 8745-8762, 2017.

Scherrer, S. C., Croci-Maspoli, M., Schwierz, C., and Appenzeller, C.: Two-dimensional indices of atmospheric blocking and their statistical relationship with winter climate patterns in the EuroAtlantic region, Int. J. Climatol., 26, 233-249, 2006.

Schnase, J. L., Lee, T. J., Mattmann, C. A., Lynnes, C. S., Cinquini, L., Ramirez, P. M., Hart, A. F., Williams, D. N., Waliser, D., Rinsland, P., Webster, W. P., Duffy, D. Q., McInerney, M. A., Tamkin, G. S., Potter, G. L., and Carriere, L.: Big data challenges in climate science: Improving the next-generation cyberinfrastructure, IEEE Geosci. Remote Sens. Mag., 4, 10-22, 2016.

Schultz, D. M., Bosart, L. F., Colle, B. A., Davies, H. C., Dearden, C., Keyser, D., Martius, O., Roebber, P. J., Steenburgh, W. J., Volkert, H., and Winters, A. C.: Extratropical cyclones: A century of research on meteorology's centerpiece, Meteorol. Monogr., 59, 16.1-16.56, https://doi.org/10.1175/AMSMONOGRAPHS-D-18-0015.1, 2019.

Shields, C. A., Rutz, J. J., Leung, L.-Y., Ralph, F. M., Wehner, M., Kawzenuk, B., Lora, J. M., McClenny, E., Osborne, T., Payne, A. E., Ullrich, P., Gershunov, A., Goldenson, N., Guan, B., Qian, Y., Ramos, A. M., Sarangi, C., Sellars, S., Gorodetskaya, I., Kashinath, K., Kurlin, V., Mahoney, K., Muszynski, G., Pierce, R., Subramanian, A. C., Tome, R., Waliser, D., Walton, D., Wick, G., Wilson, A., Lavers, D., Prabhat, Collow, A., Krishnan, H., Magnusdottir, G., and Nguyen, P.: Atmospheric River Tracking Method Intercomparison Project (ARTMIP): project goals and experimental design, Geosci. Model Dev., 11, 2455-2474, https://doi.org/10.5194/gmd-11-2455-2018, 2018.
Small, R. J., Msadek, R., Kwon, Y.-O., Booth, J. F., and Zarzycki, C.: Atmosphere surface storm track response to resolved ocean mesoscale in two sets of global climate model experiments, Clim. Dynam., 52, 2067-2089, 2019.

Stansfield, A. M., Reed, K. A., Zarzycki, C. M., Ullrich, P. A., and Chavas, D. R.: Assessing tropical cyclones' contribution to precipitation over the Eastern United States and sensitivity to the variable-resolution domain extent, J. Hydrometeorol., 21, 14251445, 2020.

Steptoe, H., Savage, N. H., Sadri, S., Salmon, K., Maalick, Z., and Webster, S.: Tropical cyclone simulations over Bangladesh at convection permitting $4.4 \mathrm{~km} \& 1.5 \mathrm{~km}$ resolution, Sci. Data, 8 , $1-12,2021$.

Ullrich, P. A.: TempestExtremes User Guide, available at: https://climate.ucdavis.edu/tempestextremes.php (last access: 15 July 2021), 2020.

Ullrich, P. A.: TempestExtremes GitHub Repository, GitHub, https://github.com/ClimateGlobalChange/tempestextremes, last access: 15 July 2021.

Ullrich, P. A. and Zarzycki, C. M.: TempestExtremes: a framework for scale-insensitive pointwise feature tracking on unstructured grids, Geosci. Model Dev., 10, 1069-1090, https://doi.org/10.5194/gmd-10-1069-2017, 2017.

Ullrich, P. A., Jablonowski, C., Kent, J., Lauritzen, P. H., Nair, R., Reed, K. A., Zarzycki, C. M., Hall, D. M., Dazlich, D., Heikes, R., Konor, C., Randall, D., Dubos, T., Meurdesoif, Y., Chen, X., Harris, L., Kühnlein, C., Lee, V., Qaddouri, A., Girard, C., Giorgetta, M., Reinert, D., Klemp, J., Park, S.-H., Skamarock, W., Miura, H., Ohno, T., Yoshida, R., Walko, R., Reinecke, A., and Viner, K.: DCMIP2016: a review of non-hydrostatic dynamical core design and intercomparison of participating models, Geosci. Model Dev., 10, 4477-4509, https://doi.org/10.5194/gmd-104477-2017, 2017.

Ullrich, P. A., Pinheiro, M. C., Stachowicz, K., and Zarzycki, C. M.: ClimateGlobalChange/tempestextremes: Version 2.1, Zenodo, https://doi.org/10.5281/zenodo.4385656, 2021.

Vishnu, S., Boos, W., Ullrich, P., and O'Brien, T.: Assessing historical variability of South Asian monsoon lows and depressions with an optimized tracking algorithm, J. Geophys. Res.-Atmos., 125, e2020JD032977. https://doi.org/10.1029/2020JD032977, 2020.

Vitart, F., Anderson, J., and Stern, W.: Simulation of interannual variability of tropical storm frequency in an ensemble of GCM integrations, J. Climate, 10, 745-760, 1997.

Walsh, K. J. E., Camargo, S. J., Vecchi, G. A., Daloz, A. S., Elsner, J., Emanuel, K., Horn, M., Lim, Y.-K., Roberts, M., Patricola, C., Scoccimarro, E., Sobel, A. H., Strazzo, S., Villarini, G., Wehner, M., Zhao, M., Kossin, J. P., LaRow, T., Oouchi, K., Schubert, S., Wang, H., Bacmeister, J., Chang, P., Chauvin, F., Jablonowski, C., Kumar, A., Murakami, H., Ose, T., Reed, K. A., Saravanan, R., Yamada, Y., Zarzycki, C. M., Vidale, P. L., Jonas, J. A., and Henderson, N.: Hurricanes and climate: The U.S. CLIVAR working group on hurricanes, B. Am. Meteorol. Soc., 96, 997-1017, https://doi.org/10.1175/BAMS-D-13-00242.1, 2015.

Wing, A. A., Camargo, S. J., Sobel, A. H., Kim, D., Moon, Y., Murakami, H., Reed, K. A., Vecchi, G. A., Wehner, M. F., Zarzycki, C., and Zhao, M.: Moist static energy budget analysis of tropical cyclone intensification in high-resolution climate models, J. Climate, 32, 6071-6095, 2019. 
You, Y. and Ting, M.: Observed Trends in the South Asian Monsoon Low-Pressure Systems and Rainfall Extremes Since the Late 1970s, Geophys. Res. Lett., 48, e2021GL092378, https://doi.org/10.1029/2021GL092378, 2021.

Zarzycki, C. M.: Tropical cyclone intensity errors associated with lack of two-way ocean coupling in high-resolution global simulations, J. Climate, 29, 8589-8610, 2016.

Zarzycki, C. M.: Projecting changes in societally impactful northeastern US snowstorms, Geophys. Res. Lett., 45, 12-067, 2018.

Zarzycki, C. M. and Ullrich, P. A.: Assessing sensitivities in algorithmic detection of tropical cyclones in climate data, Geophys. Res. Lett., 44, 1141-1149, 2017.

Zarzycki, C. M., Thatcher, D. R., and Jablonowski, C.: Objective tropical cyclone extratropical transition detection in highresolution reanalysis and climate model data, J. Adv. Model. Earth Sy., 9, 130-148, 2017.

Zarzycki, C. M., Ullrich, P. A., and Reed, K. A.: Metrics for evaluating tropical cyclones in climate data, J. Appl. Meteorol. Climatol., 60, 643-660, 2021.

Zender, C. S.: Analysis of self-describing gridded geoscience data with netCDF Operators (NCO), Environ. Model. Softw., 23, 1338-1342, https://doi.org/10.1016/j.envsoft.2008.03.004, 2008.

Zhang, W., Hari, V., and Villarini, G.: Potential impacts of anthropogenic forcing on the frequency of tropical depressions in the North Indian Ocean in 2018, J. Mar. Sci. Eng., 7, 436, https://doi.org/10.3390/jmse7120436, 2019.
Zhang, W., Villarini, G., Scoccimarro, E., and Napolitano, F.: Examining the precipitation associated with Medicanes in the highresolution ERA-5 reanalysis data, Int. J. Climatol., 41, E126E132, 2021.

Zhang, Z. and Colle, B. A.: Changes in Extratropical Cyclone Precipitation and Associated Processes during the Twenty-First Century over Eastern North America and the Western Atlantic Using a Cyclone-Relative Approach, J. Climate, 30, 8633-8656, https://doi.org/10.1175/JCLI-D-16-0906.1, 2017.

Zhao, M., Held, I. M., Lin, S.-J., and Vecchi, G. A.: Simulations of global hurricane climatology, interannual variability, and response to global warming using a 50-km resolution GCM, J. Climate, 22, 6653-6678, 2009.

Zhou, Y., O'Brien, T. A., Ullrich, P. A., Collins, W. D., Patricola, C. M., and Rhoades, A. M.: Uncertainties in Atmospheric River Lifecycles by Detection Algorithms: Climatology and Variability, J. Geophys. Res.-Atmos., 126, e2020JD033711, https://doi.org/10.1029/2020JD033711, 2021.

Zhu, Y. and Newell, R. E.: A proposed algorithm for moisture fluxes from atmospheric rivers, Mon. Weather Rev., 126, 725735, 1998. 